\title{
Modificaciones a las infracciones y sanciones de los operadores de comercio exterior según lo dispuesto en el Decreto Legislativo $N^{\circ} 1235$ y normas complementarias Modifications to the Infractions and Penalties
applied to the Foreign Trade Operators
according to the Legislative Decree $N^{\circ} 1235$
and Complementary Regulations
}

Marco Antonio Huamán Sialer* http://dx.doi.org/10.21503/lex.v15i19.1381

* Postdoctor con mención en Producción Científica. Ph. D. con mención en Estudios Legales Internacionales por la Atlantic International University, Estados Unidos de Norteamérica. Doctor en Derecho y máster en Aduanas por la UAP. Doctor en Educación por la Universidad Nacional Mayor de San Marcos. Especialista en Aduanas por la Escuela Nacional de Aduanas, hoy Instituto Aduanero y Tributario (IAT). Postgrado en Tributos Internos por la Universidad de Lima. Profesor de postgrado en la UNMSM, PUCP, ESAN, U. de Lima, U. Federico Villarreal, UNI y UAP. Actual vocal presidente de la Sala de Aduanas del Tribunal Fiscal. Miembro de la Academia Internacional de Derecho Aduanero - Capítulo Peruano. Actual presidente de la Asociación Peruana de Derecho Aduanero y Comercio Internacional (APDACI).

E-mail: m_huaman@doc.uap.edu.pe; mhuaman@mef.gob.pe

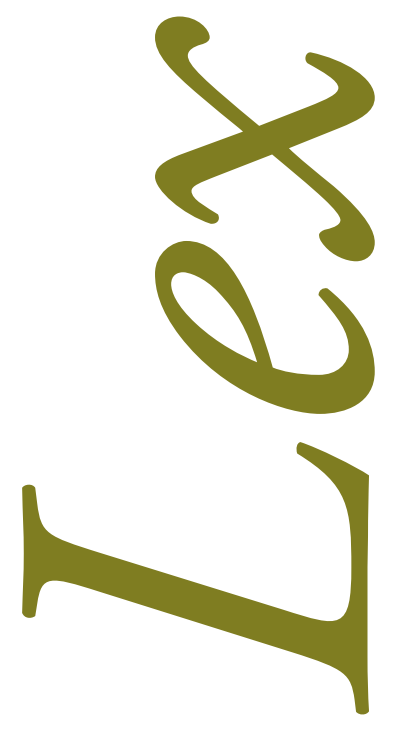




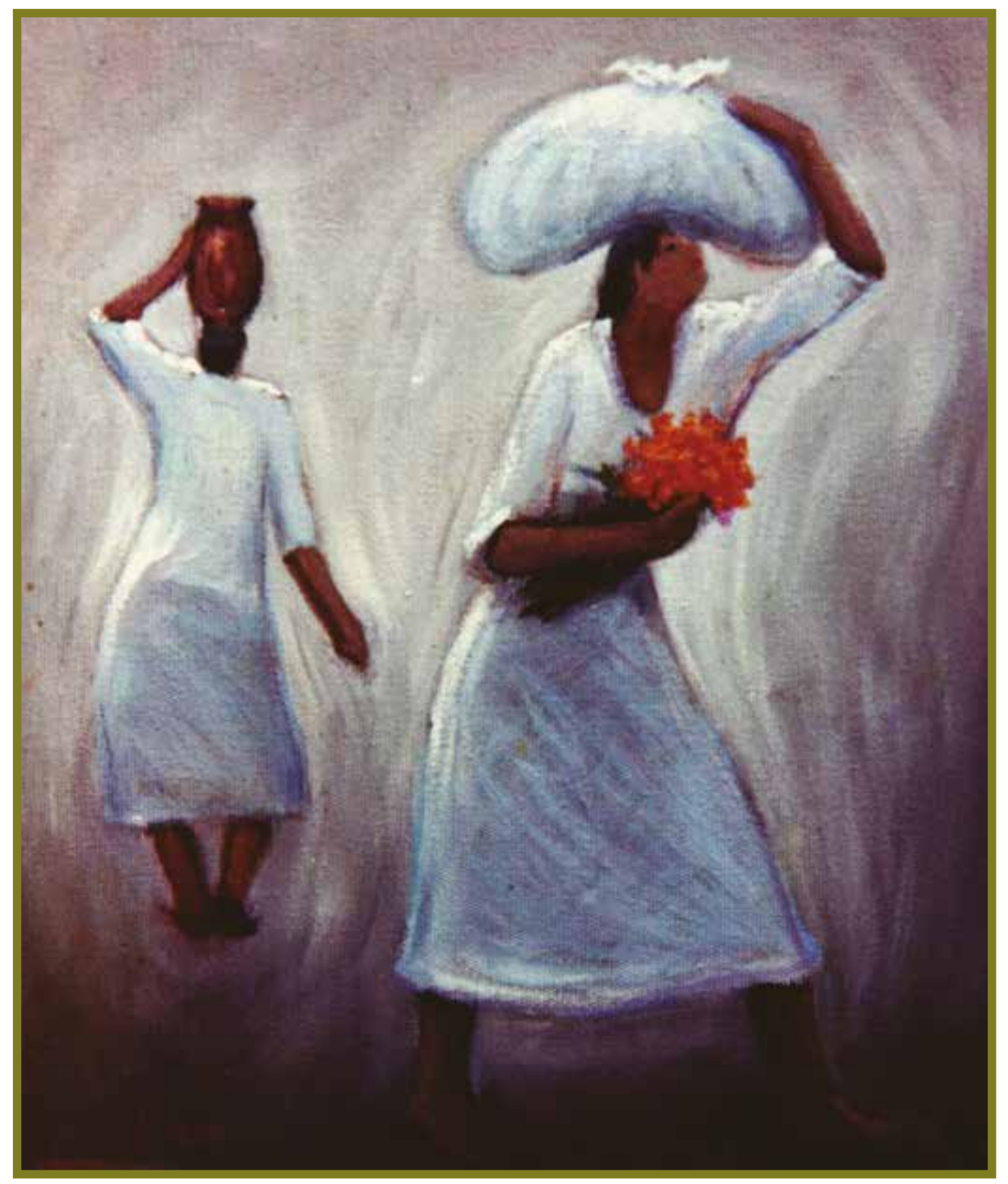

Figuras norteñas. Óscar Allaín 


\section{RESUMEN}

En el presente artículo se analizan las últimas modificaciones realizadas a la Ley General de Aduanas aprobada por Decreto Legislativo $\mathrm{N}^{\circ} 1053$ en materia de infracciones y sanciones aplicables a los distintos operadores de comercio exterior que intervienen en los procesos y/o despachos aduaneros de los regímenes de ingreso y salida de mercancías, haciendo un breve resumen de los antecedentes que motivaron dichas modificaciones; asimismo se comentan los temas más relevantes en el proceso sancionador realizado por la Administración Aduanera, resaltando los nuevos conceptos y criterios en la determinación de la infracción, aplicación de las sanciones, supuestos no sancionables y las infracciones sancionables con multa, suspensión, cancelación, inhabilitación y comiso de las mercancías, para finalmente presentar las conclusiones finales sobre la repercusión de los referidos cambios en el sistema de infracciones y sanciones aduaneras.

Palabras clave: operadores de comercio exterior, infracción aduanera, principio de legalidad, determinación de la infracción, aplicación de las sanciones, supuestos no sancionables, multa, suspensión, cancelación, inhabilitación, comiso.

\section{ABSTRACT}

This article analyzes the latest modifications made to the General Customs Law approved by Legislative Decree $\mathrm{N}^{\circ} 1053$ regarding infraction and penalties applicable to the different foreign trade operators involved in customs processes and / or customs clearance for the goods' entry and exit regimes, providing a brief summary of the background that motivated these changes. The most relevant issues regarding the sanctioning process carried out by the Customs Administration are discussed, highlighting the new concepts and criteria applied for the determination of infractions, application of penalties, non-punishable cases and infractions punishable through fine, suspension, cancellation, disqualification and confiscation of the goods, to finally present the closing conclusions on the impact of said changes on the system of customs infractions and penalties.

Key words: foreign trade operators, customs infraction, legality principle, determination of infraction, application of sanctions, non-punishable assumptions, fine, suspension, cancellation, disqualification, confiscation. 


\section{INTRODUCCIÓN}

Debemos partir por señalar que en la actualidad las Administraciones Aduaneras constituyen uno de los pilares fundamentales en el desarrollo del comercio internacional, debido a que tienen dos grandes desafíos. Por un lado facilitan el comercio exterior, y por otro realizan un óptimo control del ingreso y salida de las mercancías, tomando en cuenta la lucha frontal del comercio ilícito y el aseguramiento de la cadena logística internacional. De esta manera, las mejores prácticas a nivel mundial, en materia aduanera, han desarrollado diversas disposiciones que buscan establecer un balance entre estos dos grandes desafíos, lo que ha dado origen a diversos acuerdos a nivel multilateral, en especial los referidos a los foros de la Organización Mundial de Aduanas (OMA) ${ }^{1}$ y la Organización Mundial de Comercio (OMC). ${ }^{2}$

Ahora bien, nuestra legislación aduanera en el Perú tuvo un gran cambio de paradigma con la aprobación del Decreto Legislativo $\mathrm{N}^{\circ} 1053$, el cual estableció una nueva Ley General de Aduanas, orientada a la facilitación del comercio exterior; es así que como toda legislación vinculada a un modelo altamente cambiante, como es el comercio exterior, dicha Ley General de Aduanas fue modificada gradualmente (Decretos Legislativos $\mathrm{N}^{\circ} 1109,1122$ y 1235) con la finalidad de optimizar y simplificar los procesos aduaneros; por lo que resultaba necesario continuar con dicho proceso de perfeccionamiento normativo, actualizando nuestra legislación aduanera a los cambios en el comercio internacional e incorporando a ellas las mejores prácticas internacionales en esta materia, en particular aquellas vinculadas a la simplificación y seguridad aduanera.

De esta manera, se dispuso, entre otros temas, establecer condiciones mínimas para los puertos, aeropuertos, terminales terrestres y empresas de transporte terrestre nacional de mer-

1 Respecto del foro de la OMA, del cual el Perú es parte desde 1970, se desarrollaron el Convenio Internacional para la Simplificación y Armonización de los Procedimientos Aduaneros, o también denominado Convenio de Kyoto Revisado (CKR), y el Marco Normativo para Asegurar y Facilitar el Comercio Global, conocido como el Marco SAFE.

2 Respecto del foro de la OMC, en el 2013 se aprobó el Acuerdo sobre Facilitación de Comercio (AFC), el cual tiene como objetivo impulsar el comercio mundial estableciendo diversas disposiciones orientadas a agilizar el movimiento, levante y despacho de mercancías. 
cancías, a través de zonas de control no intrusivo y un sistema de control y monitoreo inalámbrico a los transportistas que movilizan mercancías entre lugares considerados como zonas primarias; para lo cual también se dispusieron sus obligaciones respectivas e infracciones en caso de incumplimiento. Asimismo se modificó el régimen sancionador, buscando que, si bien este desincentive las conductas ilícitas y promueva la plena seguridad de las mercancías, tutele la función esencial de la administración aduanera de facilitación del comercio, reforzando el otorgamiento de suficientes garantías al administrado en el proceso sancionador, de tal manera que la afectación o privación de sus derechos se restrinja a lo estrictamente necesario en armonía con los principios generales del derecho sancionador (legalidad, razonabilidad, proporcionalidad, entre otros).

\section{MODIFICACIONES A LAS INFRACCIONES Y SANCIONES ADUANERAS}

Previamente, debemos señalar que la base legal que sustenta el sistema de infracciones y sanciones en el Perú está dado por las siguientes normas:

- Ley General de Aduanas - Decreto Legislativo N 1053.

- Reglamento de la Ley General de Aduanas - Decreto Supremo No 010-2009-EF.

- Tabla de Sanciones Aplicables a las Infracciones previstas en la Ley General de Aduanas aprobada por Decreto Supremo No 031-2009-EF.

- T.U.O. del Código Tributario aprobado por Decreto Supremo N 133-2013-EF.

- Ley del Procedimiento Administrativo General - Ley No 27444.

- Procedimientos de Despacho (INTA-PG, INTA-PE e INTA-IT).

Es así que mediante Ley $\mathrm{N}^{\circ}$ 30335, el Congreso de la República delegó al Poder Ejecutivo la facultad de legislar mediante decreto legislativo, entre otros temas, sobre facilitar el comercio doméstico e internacional y establecer medidas para garantizar la seguridad de las operaciones de comercio internacional, así como eliminar las regulaciones excesivas que lo limiten, razón por la cual mediante Decreto Legislativo $\mathrm{N}^{\circ} 1235$ publicado en el diario oficial el peruano el 26 de setiembre de 2015, se modificó la Ley General de Aduanas, y mediante Decreto Supremo No163-2016-EF publicado en el Diario Oficial El Peruano el 22 de junio de 2016 se modificó el Reglamento de la Ley General de Aduanas.

Asimismo, mediante Decreto Supremo No 231-2016-EF publicado en el Diario Oficial El Peruano el 27 de julio de 2016, y Decreto Supremo No 295-2016-EF publicado en el Diario Oficial El Peruano el 28 de octubre de 2016, se modificó la Tabla de Sanciones Aplicables a las Infracciones. 


\section{OPERADORES DE COMERCIO EXTERIOR, PUERTOS, AEROPUERTOS Y TERMINALES TERRESTRES}

El artículo $1^{\circ}$ del Decreto Legislativo $N^{\circ} 1235$ modifica la denominación del Título II de la Sección Segunda de la Ley General de Aduanas: "TITULO II OPERADORES DEL COMERCIO EXTERIOR Y ADMINISTRADORES O CONCESIONARIOS DE LOS PUERTOS, AEROPUERTOS O TERMINALES TERRESTRES”.

Son operadores de comercio exterior los despachadores de aduana ${ }^{3}$, transportistas o sus representantes, agentes de carga internacional, almacenes aduaneros, empresas del servicio postal, empresas de servicio de entrega rápida, almacenes libres (Duty Free), beneficiarios de material de uso aeronáutico, dueños, consignatarios y en general cualquier persona natural o jurídica interviniente o beneficiaria, por sí o por otro, en los regímenes aduaneros previstos en la Ley General de Aduanas, sin excepción alguna.

Los operadores de comercio exterior desempeñan sus funciones en las circunscripciones aduaneras de la República, de acuerdo con las autorizaciones que otorga la Administración Aduanera, para lo cual deberán cumplir con los requisitos previstos por la Ley General de Aduanas y su Reglamento. Excepcionalmente se podrá ampliar la autorización de los despachadores de aduana, transportistas o sus representantes y agentes de carga internacional para que desempeñen sus funciones en otra circunscripción aduanera sin la necesidad de contar con un local en esta, de acuerdo a los criterios que establezca la Administración Aduanera. A solicitud del operador de comercio exterior, la Administración Aduanera puede revocar la autorización otorgada, siempre que el operador no registre mercancías bajo su responsabilidad, cuando corresponda. La Administración Aduanera tiene un plazo de treinta (30) días calendario, contados desde la presentación de la solicitud del operador de comercio exterior, para disponer de las mercancías en situación de abandono legal. De presentarse solicitudes de revocación y de autorización para operar como almacén aduanero en el mismo local, no es necesaria la movilización de las mercancías almacenadas si el operador que solicita autorización asume la responsabilidad por aquellas.

Por otro lado, el Decreto Legislativo No 1235 dispuso establecer nuevos elementos que permitan asegurar las mercancías bajo control aduanero, por lo que se establecieron condiciones mínimas para los administradores o concesionarios de los puertos, aeropuertos o terminales terrestres internacionales, ${ }^{4}$ estableciendo las siguientes obligaciones que ya estaban incluidas en varios artículos de la Ley General de Aduanas, pero que han sido sistematizadas para facilitar su pleno conocimiento y correcta aplicación:

3 Son despachadores de aduana los siguientes: a) Los dueños, consignatarios o consignantes; b) Los despachadores oficiales; y c) Los agentes de aduana.

4 Se debe precisar que la Ley General de Aduanas no los ha considerado como operadores de comercio exterior. 
a) Contar con la infraestructura física, los sistemas y dispositivos que garanticen la seguridad e integridad de la carga y de los contenedores o similares, de acuerdo a lo que establezca el Reglamento.

b) Proporcionar, exhibir, entregar o transmitir la información o documentación que se le requiera, en la forma, plazo y condiciones establecidas legalmente o por la autoridad aduanera.

c) Facilitar a la autoridad aduanera las labores de reconocimiento, inspección o fiscalización, así como prestar los elementos logísticos y brindar el apoyo para estos fines.

d) Implementar las medidas operativas de seguridad dispuestas por la autoridad aduanera, así como cautelar y mantener la integridad de estas o de las que hubieran sido implementadas por la Administración Aduanera o por los operadores de comercio exterior por disposición de la autoridad aduanera, según corresponda.

e) Poner a disposición de la autoridad aduanera las instalaciones, infraestructura, equipos y medios que permitan el ejercicio del control aduanero.

f) Permitir el acceso a sus sistemas de control y seguimiento para las acciones de control aduanero, de acuerdo a lo que establezca la Administración Aduanera.

g) Permitir a la Administración Aduanera la instalación de sistemas y dispositivos para mejorar sus acciones de control.

h) Otras que se establezcan en el Reglamento de la Ley General de Aduanas.

\section{INFRACCIÓN ADUANERA}

Se ha definido la infracción como la violación de la legislación aduanera.

Si no hay obligación, no puede haber infracción y menos sanción; asimismo, si no hay tipificación de infracción, no puede haber sanción. En obligaciones, sanciones e infracciones generales y específicas de los operadores de comercio exterior se le da a cada uno un tratamiento individual según su participación en la cadena logística.

Por tanto, de acuerdo al crecimiento y desarrollo de la actividad comercial a nivel mundial, se hace necesario tener un mayor control aduanero al momento de realizar el proceso de despacho de las mercancías que ingresan o salen de nuestro país, con el fin de evitar el incumplimiento de las obligaciones aduaneras por parte de los operadores de comercio exterior. Por ello, el incumplimiento de lo estipulado en la legislación aduanera trae como consecuencia 
que se cometa la infracción, la cual conlleva a que la misma sea sancionable, ${ }^{5}$ ya sea con una multa, suspensión, cancelación, inhabilitación o comiso de las mercancías.

Citando a Juan Patricio Cotter, ${ }^{6}$ este señala que la determinación de la naturaleza jurídica de las multas aduaneras y tributarias ha dividido desde hace muchos años a la doctrina y a la jurisprudencia. Para una primera tesis, la multa tiene carácter penal; para la segunda, tiene naturaleza civil o administrativa. Asimismo, el citado autor señala que el Código Aduanero consideró adecuada la elaboración de un capítulo de "disposiciones generales", en el cual se determinaron los principales fundamentos de derecho penal aplicables a las infracciones aduaneras, derogando de esta manera el principio de responsabilidad objetiva que regía anteriormente.

Además, resulta de vital importancia que la Administración Aduanera dé a conocer cada una de las situaciones que constituye infracción aduanera, pues ello permitirá que los operadores de comercio exterior tengan mayor conocimiento de aquellas actividades que perjudican en gran medida al comercio internacional y más aún a nuestro país.

Cabe precisar que antes de la entrada en vigencia de la nueva Ley General de Aduanas aprobada por Decreto Legislativo $N^{\circ} 1053$, la Sala de Aduanas del Tribunal Fiscal, mediante Resolución del Tribunal Fiscal № 06067-A-2006, dispuso lo siguiente:

(...) conforme al artículo $102^{\circ}$ del TUO de la LGA (...), corresponde determinar la comisión de infracciones con objetividad, es decir, atendiendo a los hechos objetivos y no a la posible intencionalidad del infractor, por lo que no procede invocar la falta de responsabilidad, desconocimiento de los hechos, para pretender desvirtuar la infracción cometida.

Asimismo, mediante Resolución del Tribunal Fiscal N 18373-A-2011, también se dispuso lo siguiente:

(...) la mercancía al momento de la intervención de la Aduana estaba en la zona de aplicación del Convenio Peruano-Colombiano y Ley de la Amazonía, y por tanto aún no había salido de esta y lo que el recurrente pretendía era internarla a zona tributaria común, sin cumplir con los requisitos (...)

(...) la tentativa en los delitos contemplados en la Ley de los Delitos Aduaneros está prevista en el artículo $9^{\circ}(\ldots)$;

(...) conforme el artículo $33^{\circ}$ de la citada norma: (...), dispositivo legal que determina los supuestos de infracción en el marco de la Ley de los Delitos Aduaneros, no contempla como tal lo señalado en el referido artículo $9^{\circ}$ y por tanto no se puede considerar que el intento de incurrir en la falta administrativa constituye infracción sancionable (...);

Se denomina sanción a la pena que una ley o un reglamento establece para sus infractores.

6 Juan Patricio Cotter, Las infracciones aduaneras, segunda edición (Buenos Aires: Abeledo Perrot, 2013), 98-100. 
(...) de acuerdo al artículo $189^{\circ}$ de la LGA, la calificación o determinación de infracciones en materia aduanera es objetiva, debiendo existir la violación de un deber legal para considerar que se ha cometido infracción, lo cual no ocurre en el presente caso.

Como se puede apreciar de estos fallos, la Sala de Aduanas del Tribunal Fiscal ha aplicado la responsabilidad objetiva en el caso de sanciones de multa, pues así lo disponía la Ley General de Aduanas; sin embargo, consideramos que con la nueva modificación, la Sala de Aduanas tendrá en cuenta los alcances de responsabilidad subjetiva en los casos de sanciones de suspensión, cancelación e inhabilitación.

\section{PRINCIPIO DE LEGALIDAD}

Las infracciones aduaneras se encuentran basadas en el principio de legalidad, según lo dispuesto en el artículo $188^{\circ}$ de la Ley General de Aduanas; es decir, para que un hecho sea calificado como infracción aduanera, debe estar previsto en la forma que establecen las leyes, previamente a su realización, y por tanto no procede aplicar sanciones por interpretación extensiva de la norma. En el mismo sentido, encontramos que el Código Tributario también dispone que la Administración Tributaria ejercerá su facultad de imponer sanciones de acuerdo con los principios de legalidad, tipicidad, non bis in idem, proporcionalidad, no concurrencia de infracciones y otros principios aplicables. Vale decir que la Administración Tributaría debe determinar la infracción de manera objetiva, evitando incurrir en interpretaciones extensivas de la norma y ciñéndose expresamente a lo estipulado en la ley para efecto de analizar si una determinada conducta constituye infracción sancionable.

El principio de legalidad en materia sancionatoria impide que se pueda atribuir la comisión de una falta si esta no está previamente determinada en la ley, y también prohíbe que se pueda aplicar una sanción si esta no está también determinada por la ley ${ }^{7}$.

Citando nuevamente a Juan Patricio Cotter, ${ }^{8}$ este señala que en relación con las infracciones aduaneras, el Tribunal Superior Argentino ha reconocido expresamente el principio de legalidad, al señalar que el derecho represivo aduanero no tolera ningún tipo de integración por analogía tendiente a completar los elementos esenciales de las figuras creadas por Ley (Corte Sup., 23/8/1983, "Panamericana de Plásticos S. A.”, Fallos 305:293, ED105-730).

Complementando lo antes señalado, tenemos que Julio Carlos Lascano9 señala que, entre los principios generales en materia de infracciones, se tiene la consagración a nivel aduanero del viejo principio nullum crimen, nula pena sine lege. Este principio, generalmen-

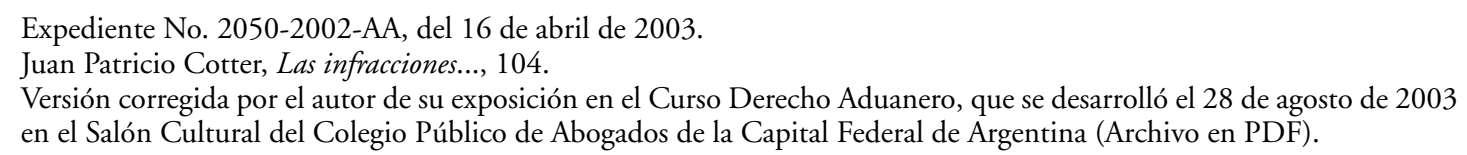


te, es traducido como "no hay delito o no hay infracción sin ley previa", por lo que este principio, que es de una importancia enorme, puede ser reformulado en el sentido de que "está permitido hacer todo aquello que no esté expresamente prohibido por el Estado mediante una ley que, con anterioridad al hecho, describa típicamente la conducta delictiva o infraccional y especifique sus sanciones". Es así que este principio general tiene su sustento o base dogmática en la Constitución, en las leyes y en el Código Aduanero, el cual se puede desglosar en ciertas reglas separadas (reserva, monopolio estatal, irretroactividad relativa, tipicidad, etc.), pero todas juntas forman este principio que se conoce como "principio de legalidad".

Finalmente citando a Juan Carlos Morón Urbina, ${ }^{10}$ este señala que el principio de legalidad se desdobla, por otra parte, en tres elementos esenciales e indisolubles: la legalidad formal, que exige el sometimiento al procedimiento y a las formas; la legalidad sustantiva, referente al contenido de las materias que le son atribuidas, constitutivas de sus propios límites de actuación; y la legalidad teleológica, que obliga al cumplimiento de los fines que el legislador estableció, en forma tal que la actividad administrativa es una actividad funcional. Asimismo, el citado autor sostiene que debe apreciarse la legalidad del acto administrativo en función del tipo de norma legal que le sirva de sustento, de ahí que se hace importante definir si el acto administrativo ejecuta una norma legal imperativa, taxativa, facultativa o discrecional, dado que para que un acto administrativo sea legal debe apreciarse si guarda una relación de conformidad con las normas imperativas y taxativas que le sirvan de referente, y, en caso de tratarse de la ejecución de normas facultativas o discrecionales, el acto administrativo deberá responder a la relación de no contrariedad.

\section{DETERMINACIÓN DE LA INFRACCIÓN}

Según lo dispuesto en el artículo $189^{\circ}$ de la Ley General de Aduanas, la infracción será determinada en forma objetiva y podrá ser sancionada administrativamente con multas, comiso de mercancías, suspensión, cancelación o inhabilitación para ejercer actividades. La Administración Aduanera aplicará las sanciones por la comisión de infracciones, de acuerdo con las tablas que se aprobarán por decreto supremo.

$\mathrm{Al}$ respecto cabe señalar, como mencionáramos en párrafos anteriores, que en Argentina la infracción se determina bajo la responsabilidad subjetiva y no objetiva como ocurre en nuestro país, al considerar que se debe aplicar los principales fundamentos de derecho penal a las infracciones aduaneras.

10 Juan Carlos Morón Urbina, Comentarios a la Ley del Procedimiento Administrativo General, undécima edición (Lima: Gaceta Jurídica, 2015), 64-65. 
Por otro lado, según lo mencionado por el autor Iván Chu del Águila, ${ }^{11}$ el modelo de Estados Unidos de Norteamérica constituye uno de los mejores ejemplos respecto de cómo un sistema de infracciones basado en un esquema de responsabilidad subjetiva puede coexistir de manera exitosa con un entorno social que denota un notable índice de cumplimiento voluntario. Asimismo, señala que dichos sistemas contienen un elemento esencial de equidad, pues permiten evitar la imposición de la sanción en tanto se acredite la falta de dolo o culpa en el incumplimiento de la respectiva obligación, además de tener en consideración la buena fe y estándares de racionalidad. Es importante mencionar que la determinación respecto a si el contribuyente actuó con una causa razonable y con buena fe es realizada en cada caso en concreto, tomando en consideración todos los hechos y circunstancias aplicables a la situación respectiva.

Como se puede apreciar, el Perú aún mantiene la tesis de la responsabilidad objetiva para la aplicación de las sanciones de multa y comiso; sin embargo, para las sanciones de suspensión, cancelación e inhabilitación, mediante el Decreto Legislativo $\mathrm{N}^{\circ} 1235$, extremo que desarrollaremos más adelante, se dispuso que se debe tener en cuenta los hechos y las circunstancias que se hubiesen presentado respecto a la comisión de la infracción, lo que pone en evidencia la aplicación de la responsabilidad subjetiva que se aplica en países como Argentina y Estados Unidos de Norteamérica, constituyendo un gran avance, pues estas modificaciones tienen como objetivo la creación de un sistema de infracciones y sanciones que busque un adecuado sentido de justicia y equidad, a través de un equilibrio entre los intereses del Estado y los derechos de los operadores de comercio exterior y/o contribuyentes.

\section{APLICACIÓN DE LAS SANCIONES}

El primer párrafo del artículo $190^{\circ}$ de la Ley General de Aduanas dispone que las sanciones aplicables a las infracciones de la Ley General de Aduanas son aquellas vigentes a la fecha en que se cometió la infracción o, cuando no sea posible establecerla, las vigentes a la fecha en que la Administración Aduanera detectó la infracción.

$\mathrm{Al}$ aplicar las sanciones de suspensión, cancelación o inhabilitación se debe tener en cuenta los hechos y las circunstancias que se hubiesen presentado respecto a la comisión de la infracción, de tal manera que la sanción a imponerse sea proporcional al grado y a la gravedad de la infracción cometida. El Reglamento establecerá los lineamientos generales para la aplicación de lo dispuesto en el párrafo precedente. ${ }^{12}$

11 Iván Chu del Águila, "Infracciones tributarias en el Perú. Visión crítica a la luz del modelo estadounidense", Revista Jurídica del Perú, tomo 81 (noviembre 2007): 132, 145, 146-147.

12 Párrafos segundo y tercero incorporados al artículo $190^{\circ}$ de la Ley General de Aduanas, por el Artículo $2^{\circ}$ del Decreto Legislativo $\mathrm{N}^{\circ} 1235$, publicado el 26 de septiembre de 2015. 
En caso de cancelación o revocación de la autorización o acreditación a los operadores de comercio exterior, así como de la inhabilitación para ejercer como agente de aduana a una persona natural, la Administración Aduanera autorizará la continuación de los trámites de despacho o la entrega de las mercancías por otro operador de comercio exterior, según corresponda.

La Administración Aduanera aplica las sanciones tributarias y administrativas previstas en la ley, sin perjuicio de poner en conocimiento a la autoridad competente los casos que presentan indicios de delitos aduaneros u otros ilícitos penales. En las resoluciones, la multa será expresada en moneda nacional, aun cuando la cuantía establecida en la Tabla de Sanciones sea en dólares de los Estados Unidos de América; en estos casos, se aplicará el tipo de cambio venta de la fecha de comisión de la infracción o, cuando no sea posible establecerla, el de la fecha en que la Administración Aduanera detectó la infracción.

A efectos de aplicar las sanciones de suspensión, cancelación o inhabilitación, se debe tener en cuenta los siguientes lineamientos generales, dispuestos en el artículo $248^{\circ}$ del Reglamento de la Ley General de Aduanas aprobado por Decreto Supremo $N^{\circ} 010-2009-E F{ }^{13}$ siendo que la Administración Aduanera regulará la aplicación de los criterios señalados:

a) La gravedad del daño o perjuicio económico causado (se evaluará en función al perjuicio que la conducta ilícita pueda causar al interés fiscal o al control aduanero)

El incumplimiento de las obligaciones de los operadores de comercio exterior previstas en la Ley General de Aduanas ocasiona daños o perjuicios a la Administración Aduanera, pues interfiere o afecta sus funciones de verificación, fiscalización y determinación de los tributos, lo que influye negativamente en el control aduanero, en la recaudación de tributos o en el flujo de cadena logística del comercio exterior. Por tal motivo, para establecer la intensidad de la sanción es necesario determinar previamente el daño causado.

b) La subsanación voluntaria de la conducta infractora, antes de la imputación de la infracción

Se debe tener en cuenta al momento de determinar la sanción, la subsanación voluntaria de la obligación incumplida, antes de la imputación de la infracción, vale decir antes de la notificación de la resolución que impone la sanción; la inclusión de este criterio permitirá a la Administración evaluar la conducta del infractor con posterioridad a la comisión del hecho ilícito, teniendo en cuenta su voluntad de regularizar las obligaciones incumplidas y subsanar las mismas.

13 Artículo modificado por el Artículo $1^{\circ}$ del Decreto Supremo No 163-2016-EF, publicado el 22 de junio de 2016. 
c) Las circunstancias de la comisión de la infracción (se evaluará la diligencia debida del deudor al momento de cumplir con su obligación y se tendrá en cuenta el comportamiento infraccional del deudor tributario ante la Administración Aduanera, tomando en cuenta el número de infracciones cometidas por tipo de infracción)

La normativa penal y administrativa no señala qué se entiende por "circunstancias"; sin embargo, la doctrina define dicho termino como los hechos que accidentalmente ocurren conjuntamente con los elementos descritos en el tipo infraccional, pero que son totalmente independientes de los elementos del tipo. Entre las circunstancias a tener en cuenta para determinar la sanción, se puede citar la diligencia con que actuó el infractor para tratar de evitar la infracción, el estado de necesidad que motivó la conducta, la predisposición para regularizar el incumplimiento de la obligación, la colaboración que proporcione a la administración aduanera para aclarar los hechos, entre otras.

d) La existencia o no de intencionalidad en la conducta del infractor

La sola ocurrencia de los supuestos descritos en el tipo no es suficiente para determinar la responsabilidad y aplicar la sanción, por lo que adicionalmente debe analizarse la voluntad del infractor, vale decir si su conducta y los efectos que se derivan de ella son los deseados, o si se han producido por negligencia o ausencia total de conocimiento, es decir, si actuó o no con dolo o culpa.

La incorporación de un párrafo adicional al artículo $190^{\circ}$ de la Ley General de Aduanas, tiene por finalidad alinear la legislación nacional a lo dispuesto en el numeral 3 del artículo $6^{\circ}$ del Acuerdo sobre Facilitación del Comercio de la OMC, ${ }^{14}$ que dispone que la sanción impuesta dependerá de los hechos y de las circunstancias del caso y será proporcional al grado y a la gravedad de la infracción cometida. Asimismo, se debe precisar que la Ley del Procedimiento Administrativo General - Ley N²7444, ya desarrolla el principio de razonabilidad, el cual se encuentra previsto en el numeral 3 del artículo $230^{\circ}$ que dispone: "Las autoridades deben prever que la comisión de la conducta sancionable no resulte más ventajosa para el infractor que cumplir las normas infringidas o asumir la sanción...”.

Al respecto, Juan Carlos Morón Urbina ${ }^{15}$ señala que el principio de razonabilidad aplicable a la potestad sancionadora se ejerce a fin de evitar dos extremos agraviantes, como son la

14 Mediante Decreto Supremo No 044-2016-RE publicado en el Diario Oficial El Peruano, de fecha 07 de julio de 2016, se ratificó el "Protocolo de Enmienda del Acuerdo de Marrakech por el que se establece la Organización Mundial del Comercio”. Con fecha 22 de febrero de 2017, dos tercios de los miembros de la Organización Mundial del Comercio han aceptado el "Protocolo de Enmienda del Acuerdo de Marrakech por el que se establece la Organización Mundial del Comercio", de forma tal que, al haber entrado en vigencia dicho acuerdo el 22 de febrero de 2017, mediante Decreto Supremo No 002-2017-MINCETUR, se dispone su puesta en ejecución.

15 Juan Carlos Morón Urbina, Comentarios..., 757-762. 
infrapunición (constituido por la punición diminuta o pequeña que implica que la sanción no llega a ser disuasiva sino más bien genera un costo que se puede asumir en aras de obtener el beneficio ilegitimo que la conducta ilegal la pueda reparar) y el exceso de punición (en la norma o el acto disciplinario se contienen sanciones aplicables o aplicadas que resultan siendo desproporcionadas con las conductas sancionables o sancionadas respectivamente). Asimismo señala que el juicio de proporcionalidad consiste en que el grado de la sanción guarde una relación equivalente o proporcional (ventajas y desventajas) con el fin que se procura alcanzar, por lo que se debe realizar una ponderación o balance de costo-beneficio de la sanción a aplicarse, entre los intereses y derechos sacrificados y el fin público que persigue la sanción, pero contextualizándolo con los hechos y circunstancias determinantes de la responsabilidad del infractor; todo ello implica que la medida administrativa debe mantener la debida proporción entre los medios a emplear y los fines públicos que debe tutelar.

Además, el Tribunal Constitucional, al analizar el artículo $27^{\circ}$ del Decreto Legislativo $\mathrm{N}^{\circ}$ 276, ha precisado, a través de la sentencia recaída en el Expediente $N^{\circ}$ 2192-2004-AA/TC lo siguiente:

...en el momento de establecer una sanción administrativa, no se limite a realizar un razonamiento mecánico de aplicación de normas, sino que, además, efectúe una apreciación razonable de los hechos en relación con quien los hubiese cometido; es decir, que no se trata solo de contemplar los hechos en abstracto, sino "en cada caso" y tomando en cuenta "los antecedentes del servidor". Por tanto, una decisión razonable en estos casos supone, cuando menos:

a) La elección adecuada de las normas aplicables al caso y su correcta interpretación, tomando en cuenta no solo una ley particular, sino el ordenamiento jurídico en su conjunto.

b) La comprensión objetiva y razonable de los hechos que rodean al caso, que implica no sólo una contemplación en "abstracto" de los hechos, sino su observación en directa relación con sus protagonistas, pues solo así un "hecho" resultará menos o más tolerable, confrontándolo con los "antecedentes del servidor", como ordena la ley en este caso.

c) Una vez establecida la necesidad de la medida de sanción, porque así lo ordena la ley correctamente interpretada en relación a los hechos del caso que han sido conocidos y valorados en su integridad, entonces el tercer elemento a tener en cuenta es que la medida adoptada sea la más idónea y de menor afectación posible a los derechos de los implicados en el caso....

De esta manera podemos apreciar que la legislación aduanera en el Perú da un paso muy importante al incorporar la aplicación de la responsabilidad subjetiva a la aplicación de las sanciones de suspensión, cancelación e inhabilitación, que es la facultad de la Administración Aduanera destinada a aplicar los hechos y circunstancias para determinar la gravedad de la 
infracción, la cual se encuentra prevista en el artículo $248^{\circ}$ del Reglamento de la Ley General de Aduanas antes mencionado, de tal manera que la sanción a imponerse sea la más adecuada y proporcional al acto cometido, cuidando de que no resulte irrisoria respecto del beneficio que el infractor podría obtener con la transgresión de la obligación incumplida.

\section{SUPUESTOS NO SANCIONABLES}

Los supuestos no sancionables son situaciones en las que se vuelve inexistente el efectivo nexo causal entre la conducta del operador de comercio exterior y la obligación vulnerada; en ese sentido, se agregan dos supuestos adicionales al artículo $191^{\circ}$ de la Ley General de Aduanas, quedando redactado de la siguiente manera:

No serán sancionables las infracciones derivadas de:

a) Errores en las declaraciones o relacionados con el cumplimiento de otras formalidades aduaneras que no tengan incidencia en los tributos o recargos y que puedan ser determinados de la simple observación de los documentos fuente pertinentes siempre que se trate de:

1. Error de trascripción: Es el que se origina por el incorrecto traslado de información de una fuente fidedigna a una declaración o a cualquier otro documento relacionado con el cumplimiento de formalidades aduaneras, siendo posible de determinar de la simple observación de los documentos fuente pertinentes;

2. Error de codificación: Es el que se produce por la incorrecta consignación de los códigos aprobados por la autoridad aduanera en la declaración aduanera de mercancías o cualquier otro documento relacionado con el cumplimiento de formalidades aduaneras, siendo posible de determinar de la simple observación de los documentos fuente pertinentes.

b) Hechos que sean calificados como caso fortuito o fuerza mayor; o

c) Fallas en los sistemas internos o falta de implementación informática, atribuibles a la SUNAT.

Esta modificación tiene como finalidad que de manera automática y sin necesidad de informe previo de evaluación, estos hechos puedan generar la no aplicación de la sanción que hubiese correspondido aplicar.

Además, es preciso señalar que cuando ocurre un caso fortuito o de fuerza mayor, se produce un mecanismo de liberación del deudor ante el incumplimiento de una obligación tributaria en virtud del principio de causalidad y del principio que establece que a lo imposible nadie está obligado y que el derecho no tiene por finalidad concretar injusticia. Por otro lado, los sistemas automatizados de información en las aduanas no están ajenos a contingencias, las cuales pueden generar en determinados momentos fallas o inducción a errores para con los 
administrados y que no podrían dar lugar a la aplicación de sanciones, en tanto son situaciones que no resultan imputables a los mismos.

Con relación al tema de supuestos no sancionables, la Sala de Aduanas del Tribunal Fiscal, con anterioridad a las modificaciones realizadas al artículo $191^{\circ}$, mediante la Resolución del Tribunal Fiscal Nº2999-A-2015 emitida el 23 de marzo de 2015, dispuso lo siguiente:

... Que el sólo hecho que existan inconvenientes para la transmisión oportuna de la tarja al detalle a causa de la conclusión de un trámite administrativo por parte de la Administración Aduanera, dentro del plazo que tenía la recurrente para poder cumplir con su obligación y de esta manera no incurrir en multa, genera un hecho no imputable a la recurrente y que escapa a su esfera de control...

... Que en consecuencia, las infracciones que se configuran como consecuencia de hechos imputables a terceros que a su vez impliquen una acción por parte de la Administración Aduanera no resultan sancionables, siempre y cuando se encuentren debidamente acreditados...

Asimismo, la Resolución del Tribunal Fiscal Nº3247-A-2016 emitida el 04 de abril de 2016 estableció lo siguiente:

... se tiene que los servicios informáticos utilizados para realizar procesos de ingreso y salida de mercancía dentro de la jurisdicción de la Aduana Marítima del Callao no estaban disponibles desde el viernes 07/12/2012 a las 22:00 horas hasta el domingo 09/12/2012 a las 10:00 horas...

... el solo hecho que se haya suspendido el servicio informático a causa de la Administración Aduanera, dentro del plazo que tenía la recurrente para poder cumplir con su obligación y de esta manera no incurrir en multa, genera un hecho no imputable a la recurrente y que escapa a su esfera de...

... en consecuencia, las infracciones que se configuran como consecuencia de hechos imputables a la Administración Aduanera no resultan sancionables, siempre y cuando se encuentren debidamente acreditados...

Por otro lado, con relación a hechos que sean calificados como caso fortuito o fuerza mayor, mediante la Resolución del Tribunal Fiscal № 11209-A-2015 emitida el 17 de noviembre de 2015, se dispuso lo siguiente:

... La falta o pérdida de mercancía a que se refiere el presente caso no es consecuencia de un hecho de fuerza mayor (artículo $1315^{\circ}$ del Código Civil), es decir, no es consecuencia de un evento extraordinario, imprevisible e irresistible, que ha impedido a la empresa recurrente cumplir con su obligación de custodiar la mercancía en aplicación del artículo $31^{\circ}$ de la Ley General de Aduanas, en concordancia con el artículo $13^{\circ}$ del Decreto Supremo No $008-95-E F . .$. 
... se encuentra acreditado que como consecuencia del reconocimiento físico efectuado en el depósito temporal se detectó mercancía faltante, toda vez que en lugar del teléfono Iphone 5 se reconoció físicamente un teléfono celular usado marca Samsung que corresponde a una línea nacional, configurándose el supuesto de hecho de la infracción materia de grado...

Es así que en el caso antes citado, el deposito temporal no pudo acreditar el caso fortuito o fuerza mayor, toda vez que la falta o pérdida de mercancía no es consecuencia de un evento extraordinario, imprevisible e irresistible, que impida que un almacén aduanero cumpla con su obligación de custodiar la mercancía en aplicación de lo dispuesto en la Ley General de Aduanas.

Por otro lado, se tiene que mediante la Resolución del Tribunal Fiscal № 06381-A-2015, el dueño y/o consignatario de la mercancía sí pudo acreditar la fuerza mayor, pues la Sala de Aduanas dispuso lo siguiente:

(...) Juzgado Penal de Lima - Reos Libres concluyó que está plenamente acreditado que el 31 de julio de 2008 se produjo la sustracción, es decir, el hurto del camión semitráiler remolcador (...) transportando un contenedor de 40 pies (...); sin embargo, al no existir elementos suficientes para determinar que (...) tuvo participación dolosa en el evento incriminado, se declara sobreseída la causa penal seguida contra el Sr. Vega (...) por la comisión del delito contra el patrimonio - hurto agravado en agravio de la empresa recurrente;

(...) habiendo señalado el Juez Penal que se encuentra plenamente acreditado el hurto, se ha determinado que la pérdida de la mercancía es consecuencia de un caso de fuerza mayor según lo establecido en el artículo $1315^{\circ}$ del Código Civil, es decir, que es consecuencia de evento extraordinario, imprevisible e irresistible, que ha impedido a la empresa recurrente cumplir con su obligación de custodiar la mercancía hasta su entrega al depósito aduanero autorizado.

Se debe considerar que alrededor del territorio nacional se realizan huelgas de los trabajadores del puerto, paralizaciones del transporte, cierre de avenidas, inundaciones, huaicos, temblores, entre otros, los cuales califican como casos fortuitos o de fuerza mayor y afectan el cumplimiento de las obligaciones tributarias aduaneras por parte de los operadores de comercio exterior, específicamente los plazos, derivando en la configuración de infracción; debiéndose tener en cuenta que, por sí, dichas eventualidades generan costos adicionales a los operadores de comercio exterior por el retraso en el despacho de sus mercancías y el incumplimiento de sus compromisos con sus clientes y proveedores; y si a ello se le agrega la aplicación de sanciones en casos en los que no han sido responsables por la infracción, su situación se vería aún más perjudicada, ocasionado que se vuelvan menos competitivos frente a sus competidores; es por esa razón que dichos casos excepcionales de caso fortuito y fuerza mayor debidamente acreditados no generan sanción alguna. 
También, se tiene que con relación a la fuerza mayor, mediante Resolución del Tribunal Fiscal No 10179-A-2016 se dispuso lo siguiente:

Que también se debe indicar que conforme con el criterio establecido por este Tribunal en la Resolución del Tribunal Fiscal $N^{\circ}$ 06967-8-2015, entre otras, la fuerza mayor consiste en un evento inusual (extraordinario), no esperado al no existir elementos para considerar que este pueda ocurrir (imprevisible), independiente de la voluntad del deudor (proveniente de terceros) y ajeno a su control o manejo (irresistible), que imposibilita la ejecución de la obligación o determina su cumplimiento parcial, tardío o defectuoso;

Que en el caso de autos la recurrente para acreditar la causal de fuerza mayor presenta los Oficios No 137-2010-GRU-DRSTC-DCT y No 429-2010-GR-Ucayali-DRSTC-DR emitidos en Pucallpa el 27 de agosto de 2010 y el 24 de setiembre de 2010 por la Dirección Regional Sectorial de Transportes y Comunicaciones del Gobierno Regional de Ucayali que dan cuenta del bloqueo la Carretera Central, en los sectores del kilómetro 118+000 Shiringal Bajo, hasta el kilómetro 214+500 la Divisoria, en las siguientes fechas:

- Primera etapa del bloqueo: 03 de agosto - 09 de agosto de 2010.

- Segunda etapa del bloqueo: 18 de agosto - 28 de agosto de 2010

- Tercera etapa del bloqueo: 10 de setiembre - 20 de setiembre de 2010

Que al respecto cabe acotar que incluso en las fojas 41-42 de estos actuados consta el Informe $\mathrm{N}^{\circ}$ 1837-2010-SUNAT/3T0020 de fecha 07 de setiembre de 2010 emitido por la Aduana de Pucallpa, conforme el cual se plantea que resulta procedente el pedido planteado por la recurrente, por lo que el Intendente de la Aduana señalada deriva el referido informe a la Aduana de origen para su pronunciamiento (ver memorándum en la foja 49);

Que en consecuencia, siendo claro que en el caso de autos se evidencia que por causas no imputables a la recurrente, esta en las fechas señaladas se vio impedida de trasladar sus mercancías a la jurisdicción de la Aduana de Pucallpa; no corresponde que se compute dentro del plazo de 60 días para efectuar el reconocimiento físico de las mercancías solicitadas al régimen de la Ley $\mathrm{N}^{\circ} 27037$, los períodos comprendidos entre los días 03 de agosto y 09 de agosto de 2010, 18 de agosto y 28 de agosto de 2010, así como los días comprendidos entre el 10 de setiembre y el 20 de setiembre de 2010.

Con relación a los errores de transcripción, debemos precisar que mediante Resolución del Tribunal Fiscal No 00396-A-2005, que constituye jurisprudencia de observancia obligatoria, se dispuso lo siguiente:

(...) error de transcripción, (...) cuando el documento que contiene los errores señala expresamente que su información ha sido extraída del documento fidedigno o que se formula sobre la base de este, y en caso de no ser así, cuando en el documento que con- 
tiene la información errada, contiene otra información que fue copiada correctamente del documento fidedigno, de la cual se puede apreciar que tanto esta (información correcta) como la información equivocada fueron copiadas del documento fidedigno, o que el error surge de un copia que fue fiel pero parcial, es decir, solo respecto de una parte de la información.

(...) casos en los que no se puede apreciar ninguna relación entre el documento al que el usuario del servicio aduanero le atribuye la calidad de fidedigno y el documento que contiene información errada en los términos antes señalados, no es posible calificar dicha situación como un error de transcripción.

También tenemos que mediante Resolución del Tribunal Fiscal N 12872-A-2009 se dispuso lo siguiente:

(...) el error en la modalidad de despacho que figura en una declaración (...) no constituye un error con incidencia tributaria porque no afecta la obtención de tributo alguno.

(...) entre los diversos datos que afectan el efectivo control aduanero o las informaciones estadísticas (...), (...) figura el código y documento de identificación del importador o consignatario, el valor en aduana (...)

(...) en el indicado listado, no aparece la información o datos correspondientes a la modalidad de despacho o al tipo de despacho, lo que permite afirmar que el error cometido (...) no afecta el efectivo control aduanero o la información estadística

(...) efectivamente califica como un error de codificación (...) por lo que no corresponde considerar que ha incurrido en infracción sancionable (...).

La Resolución del Tribunal Fiscal N 11732-A-2011 también dispuso lo siguiente:

(...) el referido conocimiento de embarque (Conocimiento de Embarque hijo No (...) presentado por la recurrente a efecto de desvirtuar la aplicación de la sanción de multa, sí constituye la fuente fidedigna a que se refiere el citado artículo $191^{\circ}(\ldots)$

(...) descalificar el documento presentado por la recurrente como fuente fidedigna de la elaboración del manifiesto de carga desconsolidado (proceder de la Aduana), resulta un pronunciamiento contradictorio a la aceptación y despacho aduanero de las mercancías (...), que justamente se sustenta en el Conocimiento de Embarque hijo No (...).

\section{INFRACCIONES SANCIONABLES CON MULTA}

En base a la operatividad, se ha podido establecer que existen situaciones no contempladas en la Ley General de Aduanas, en las que se debería cautelar la seguridad, en especial en aquellos casos en que, a lo largo de la cadena logística, las medidas de seguridad han sido implementadas o colocadas por un operador de comercio exterior y no directamente por 
la SUNAT, como por ejemplo sucede en el caso de los precintos de seguridad. Es así que se dispuso modificar el supuesto de infracción previsto en el numeral 2 del inciso a) del artículo $192^{\circ}$ de la Ley General de Aduanas, con el objetivo de ampliar la obligación a los operadores de comercio exterior sobre las medidas de seguridad que se aplican en el proceso comercial; de esta manera se busca que estos implementen las medidas de seguridad dispuestas por la autoridad aduanera, así como cautelen y mantengan la integridad de dichas medidas, o de las que hubieran sido implementadas por la Administración Aduanera, por otro operador de comercio exterior, o por los administradores o concesionarios de los puertos, aeropuertos o terminales terrestres internacionales:

\begin{tabular}{|c|c|c|c|}
\hline & INFRACCIÓN & BASE LEGAL & SANCIÓN \\
\hline 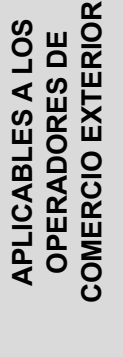 & $\begin{array}{l}\text { No implementar las medidas de se- } \\
\text { guridad dispuestas por la Aduana. } \\
\text { No cautelar, no mantener o violen- } \\
\text { tar la integridad de las medidas de } \\
\text { seguridad por otro O.C.E. o admi- } \\
\text { nistradores o concesionarios de } \\
\text { Puertos, Aeropuertos o Terminales } \\
\text { Terrestres. }\end{array}$ & $\begin{array}{c}\text { Numeral } 2 \\
\text { Inciso a } \\
\text { Art. } 192^{\circ}\end{array}$ & $\begin{array}{l}1,5 \text { del valor FOB determinado por } \\
\text { la Aduana con un mínimo de } 3 \text { UIT } \\
\text { cuando se trata de precintos o si- } \\
\text { milares. } \\
\text { En caso no se puede determinar el } \\
\text { valor FOB será de } 3 \text { UIT. } \\
3 \text { UIT para los demás casos }\end{array}$ \\
\hline
\end{tabular}

Asimismo, en la línea, vinculada al control de transportistas que movilizan mercancías entre zonas primarias, se dispuso modificar las obligaciones de los operadores de comercio exterior, a fin de establecer que solo se puede contratar a transportistas que cuenten con un sistema de control y monitoreo inalámbrico, que permitan el seguimiento de las mercancías bajo control aduanero, para lo cual se dispuso adicionar una nueva infracción sancionable con multa, conforme detallamos a continuación:

\begin{tabular}{|c|c|c|c|}
\hline \multirow[b]{2}{*}{ 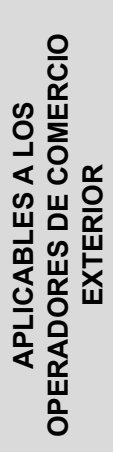 } & INFRACCIÓN & BASE LEGAL & SANCIÓN \\
\hline & $\begin{array}{l}\text { Trasladen mercancías entre lu- } \\
\text { gares considerados o habilitados } \\
\text { como zona primaria, utilizando } \\
\text { vehículos que no cuenten con un } \\
\text { sistema de control y monitoreo } \\
\text { inalámbrico que transmita la in- } \\
\text { formación del vehículo en forma } \\
\text { permanente, o no pongan dicha } \\
\text { información a disposición de la } \\
\text { Aduana. }\end{array}$ & $\begin{array}{l}\text { Numeral } 9 \\
\text { Inciso a } \\
\text { Art. } 192^{\circ}\end{array}$ & 3 UIT por cada traslado detectado. \\
\hline
\end{tabular}


Complementado lo anterior, se tiene que la infracción tipificada en el numeral 9 del inciso a) del artículo $192^{\circ}$ de la Ley General de Aduanas es una infracción que está referida al supuesto de ausencia o el no uso de dispositivos de conexión inalámbrica (GPS) en el medio de transporte terrestre que se utilice para trasladar mercancías de una zona primaria a otra, por ejemplo, en el caso del proceso de ingreso, el traslado del puerto o aeropuerto a un depósito temporal o al local del importador, y en el caso del proceso de salida, el traslado del depósito temporal o del local del exportador al puerto o aeropuerto.

Resulta pertinente indicar que la sanción pecuniaria de 3 UIT por cada traslado detectado se encuentra muy por debajo de los montos que se aplican en otros sectores para infracciones de similar naturaleza, como por ejemplo ocurre en el caso de OSINERGMIN que prevé una sanción de multa de hasta 300 UIT en los casos de ausencia de monitoreo en el transporte de combustible, a quienes se les exige mantener el normal funcionamiento del equipo GPS y/o Equipo de Supervisión del OSINERGMIN instalado en sus respectivas unidades de transporte.

Por otro lado, teniendo en cuenta que se desea preservar la cadena logística de comercio exterior, se dispuso la creación del capítulo IX en la Ley General de Aduanas, en el que se clarifican y ordenan las distintas obligaciones de los administradores o concesionarios de los puertos, aeropuertos o terminales terrestres internacionales. Es por esa razón que se incluyó el literal k) del artículo $192^{\circ}$ de la Ley General de Aduanas, estableciendo las sanciones de multa ante el incumplimiento de las obligaciones que se señalan a continuación:

\begin{tabular}{|c|c|c|c|}
\hline \multirow[b]{2}{*}{ 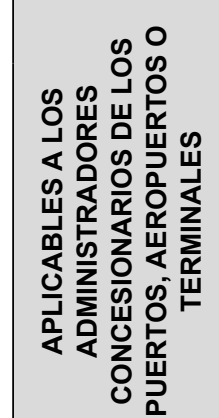 } & INFRACCIÓN & BASE LEGAL & SANCIÓN \\
\hline & $\begin{array}{l}\text { No cuenten con la infraestruc- } \\
\text { tura física, los sistemas o los } \\
\text { dispositivos que garanticen la } \\
\text { seguridad o integridad de la } \\
\text { carga o, de los contenedores o } \\
\text { similares, de acuerdo a lo que } \\
\text { establezca el Reglamento. }\end{array}$ & $\begin{array}{c}\text { Numeral } 1 \\
\text { Inciso k } \\
\text { Art. } 192^{\circ}\end{array}$ & 3 UIT \\
\hline
\end{tabular}




\begin{tabular}{|c|c|c|c|}
\hline \multirow{3}{*}{ 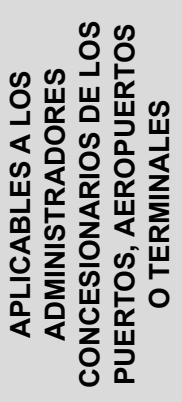 } & INFRACCIÓN & BASE LEGAL & SANCIÓN \\
\hline & $\begin{array}{l}\text { No proporcionen, exhiban, entreguen o transmitan la } \\
\text { información o documentación requerida en la forma, } \\
\text { plazo o condiciones establecidas legalmente o por la } \\
\text { autoridad aduanera. }\end{array}$ & $\begin{array}{l}\text { Numeral } 2 \\
\text { Inciso k } \\
\text { Art. } 192^{\circ}\end{array}$ & $1 \mathrm{UIT}$ \\
\hline & $\begin{array}{l}\text { Impidan u obstaculicen a la autoridad aduanera las la- } \\
\text { bores de reconocimiento, inspección o fiscalización; o } \\
\text { no presten los elementos logísticos ni brinden el apoyo } \\
\text { para estos fines. }\end{array}$ & $\begin{array}{l}\text { Numeral } 3 \\
\text { Inciso k } \\
\text { Art. } 192^{\circ}\end{array}$ & 3 UIT \\
\hline
\end{tabular}

\begin{tabular}{|c|c|c|c|}
\hline & INFRACCIÓN & BASE LEGAL & SANCIÓN \\
\hline 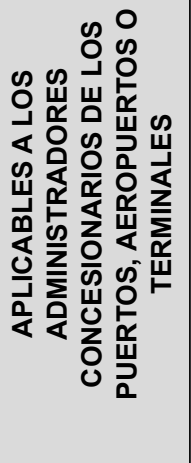 & $\begin{array}{l}\text { No implementen las medidas ope- } \\
\text { rativas de seguridad dispuestas } \\
\text { por la autoridad aduanera, o no } \\
\text { cautelen, no mantengan o violen } \\
\text { la integridad de estas o de las } \\
\text { implementadas por la Adminis- } \\
\text { tración Aduanera o por los ope- } \\
\text { radores de comercio exterior por } \\
\text { disposición de la autoridad adua- } \\
\text { nera. }\end{array}$ & $\begin{array}{c}\text { Numeral } 4 \\
\text { Inciso k } \\
\text { Art. } 192^{\circ}\end{array}$ & $\begin{array}{l}1.5 \text { del valor FOB de la mercancía } \\
\text { determinado por la aduana con un } \\
\text { mínimo de } 3 \text { UIT cuando se trate } \\
\text { de precintos o disp ositivos simi- } \\
\text { lares. } \\
\text { En el caso en que la autoridad } \\
\text { aduanera no pueda determinar el } \\
\text { valor FOB de la mercancía la mul- } \\
\text { ta es de } 3 \text { UIT. } \\
3 \text { UIT para los demás casos. }\end{array}$ \\
\hline
\end{tabular}

\begin{tabular}{|c|c|c|c|}
\hline \multirow{4}{*}{ 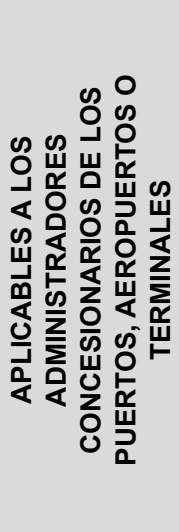 } & INFRACCIÓN & BASE LEGAL & SANCIÓN \\
\hline & $\begin{array}{l}\text { No pongan a disposición de la autoridad aduanera las } \\
\text { instalaciones, infraestructuras, equipos o medio que } \\
\text { permitan el ejercicio del control aduanero. }\end{array}$ & $\begin{array}{l}\text { Numeral } 5 \\
\text { Inciso k } \\
\text { Art. } 192^{\circ}\end{array}$ & 3 UIT \\
\hline & $\begin{array}{l}\text { No permitan el acceso a sus sistemas de control y se- } \\
\text { guimiento para las acciones de control aduanero, de } \\
\text { acuerdo a lo que establezca la Administración Adua- } \\
\text { nera. }\end{array}$ & $\begin{array}{l}\text { Numeral } 6 \\
\text { Inciso k } \\
\text { Art. } 192^{\circ}\end{array}$ & 3 UIT \\
\hline & $\begin{array}{l}\text { No permitan u obstaculicen a la Administración Adua- } \\
\text { nera la instalación de los sistemas o dispositivos para } \\
\text { mejorar sus acciones de control. }\end{array}$ & $\begin{array}{l}\text { Numeral } 7 \\
\text { Inciso k } \\
\text { Art. } 192^{\circ}\end{array}$ & 3 UIT \\
\hline
\end{tabular}


Estas nuevas infracciones buscan cautelar la seguridad de la cadena logística y el ejercicio del control aduanero, por lo que se impone la multa de 3 UIT, al ser el monto constante más alto previsto en la Tabla de Sanciones.

Otro de los aspectos importantes es que se dispuso que algunas infracciones a los operadores de comercio exterior que antes eran sancionadas con la suspensión y cancelación de actividades, ahora serán sancionadas con multa, ello con el objetivo de otorgar mayor proporcionalidad y racionalidad a las sanciones.

Sobre el particular, es preciso indicar que en algunos casos la suspensión de actividades resulta una medida excesiva, puesto que implica una paralización de labores del depósito temporal o del agente de aduana, afectando así, por un lado, a la empresa y a sus trabajadores y, por otro lado, a los dueños o consignatarios de las mercancías destinadas a un depósito temporal suspendido o que habían contratado los servicios de un agente de aduana que es suspendido; es así que estos operadores de comercio exterior al ser suspendidos no podían prestar servicios pero debían continuar pagando a sus trabajadores y afrontado sus costos permanentes; asimismo ocasionaban sobrecostos, demoras y trámites adicionales a los dueños o consignatarios.

No obstante, se debe señalar que debido a la gravedad de las conductas y por sus implicancias en la operatividad aduanera, se dispuso que estas infracciones no se encuentren beneficiadas con el régimen de incentivos en la Ley General de Aduanas.

En ese sentido, en cuanto a las infracciones relacionadas con el cumplimiento de requisitos $\mathrm{y}$ condiciones para operar $\mathrm{y}$ de infraestructura, se establecieron las siguientes multas:

\begin{tabular}{|c|c|c|c|}
\hline \multirow{3}{*}{ 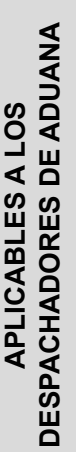 } & INFRACCIÓN & BASE LEGAL & SANCIÓN \\
\hline & $\begin{array}{l}\text { No mantengan o no se adecuen a } \\
\text { los requisitos y condiciones estable- } \\
\text { cidos para operar. }\end{array}$ & $\begin{array}{l}\text { Numeral } 11 \\
\text { Inciso b } \\
\text { Art. } 192^{\circ}\end{array}$ & $\begin{array}{l}0,1 \text { UIT por cada requisito documen- } \\
\text { tario. } \\
1 \text { UIT por cada requisito o condición } \\
\text { de infraestructura o no mantener el } \\
\text { patrimonio social. }\end{array}$ \\
\hline & $\begin{array}{l}\text { Desempeñen sus funciones en loca- } \\
\text { les no autorizados por la autoridad } \\
\text { aduanera. }\end{array}$ & $\begin{array}{l}\text { Numeral } 12 \\
\text { Inciso b } \\
\text { Art. } 192^{\circ}\end{array}$ & 1 UIT. \\
\hline
\end{tabular}




\begin{tabular}{|c|c|c|c|}
\hline \multirow{3}{*}{ 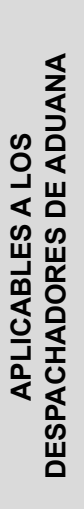 } & INFRACCIÓN & BASE LEGAL & SANCIÓN \\
\hline & $\begin{array}{l}\text { Autentiquen documentación sin con- } \\
\text { tar con el original o que corresponda } \\
\text { a un despacho en el que no haya } \\
\text { intervenido. }\end{array}$ & $\begin{array}{l}\text { Numeral } 13 \\
\text { Inciso b } \\
\text { Art. } 192^{\circ}\end{array}$ & 3 UIT \\
\hline & $\begin{array}{l}\text { Efectúen el retiro de las mercancías } \\
\text { del punto de llegada sin tener le- } \\
\text { vante, se encuentren inmovilizadas } \\
\text { o cuando no se haya autorizado su } \\
\text { salida: en los casos excepcionales } \\
\text { establecidos en la L.G.A. y su Re- } \\
\text { glamento. }\end{array}$ & $\begin{array}{l}\text { Numeral } 14 \\
\text { Inciso b } \\
\text { Art. } 192^{\circ}\end{array}$ & $\begin{array}{l}\text { Equivalente al valor FOB hasta un } \\
\text { máximo de } 20 \text { UIT y un mínimo de } 0,1 \\
\text { UIT. }\end{array}$ \\
\hline
\end{tabular}

\begin{tabular}{|c|c|c|c|}
\hline \multirow{3}{*}{ 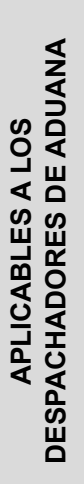 } & INFRACCIÓN & BASE LEGAL & SANCIÓN \\
\hline & $\begin{array}{l}\text { Presenten la declaración aduanera } \\
\text { de mercancías con datos distintos a } \\
\text { los transmitidos electrónicamente a } \\
\text { la Administración Aduanera o a los } \\
\text { rectificados a su fecha de presenta- } \\
\text { ción. }\end{array}$ & $\begin{array}{l}\text { Numeral } 15 \\
\text { Inciso b } \\
\text { Art. } 192^{\circ}\end{array}$ & 3 UIT \\
\hline & $\begin{array}{l}\text { Cuando la autoridad aduanera com- } \\
\text { pruebe que ha destinado mercan- } \\
\text { cías a nombre de un tercero, sin } \\
\text { contar con su autorización. }\end{array}$ & $\begin{array}{l}\text { Numeral } 16 \\
\text { Inciso b } \\
\text { Art. } 192^{\circ}\end{array}$ & $\begin{array}{l}\text { Equivalente al valor FOB hasta un } \\
\text { máximo de } 20 \text { UIT y un mínimo de } 0,1 \\
\text { UIT. }\end{array}$ \\
\hline
\end{tabular}

\begin{tabular}{|c|c|c|c|}
\hline \multirow{3}{*}{ 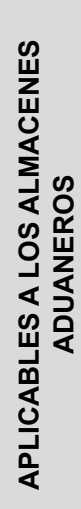 } & INFRACCIÓN & BASE LEGAL & SANCIÓN \\
\hline & $\begin{array}{l}\text { No mantengan o no se adecuen a } \\
\text { las obligaciones, los requisitos y } \\
\text { condiciones establecidos para ope- } \\
\text { rar, excepto las sancionadas con } \\
\text { multa. }\end{array}$ & $\begin{array}{l}\text { Numeral } 6 \\
\text { Inciso f } \\
\text { Art. } 192^{\circ}\end{array}$ & $\begin{array}{l}0,3 \text { UIT para cada requisito documen- } \\
\text { tario. } \\
3 \text { UIT por cada requisito de infraes- } \\
\text { tructura incumplido o por no mantener } \\
\text { el nivel de solvencia económico y fi- } \\
\text { nanciero. }\end{array}$ \\
\hline & $\begin{array}{l}\text { No destinen las áreas y recintos au- } \\
\text { torizados para fines o funciones es- } \\
\text { pecíficos de la autorización. }\end{array}$ & $\begin{array}{l}\text { Numeral } 7 \\
\text { Inciso f } \\
\text { Art. } 192^{\circ}\end{array}$ & $\begin{array}{l}1 \text { UIT por cada área o recinto auto- } \\
\text { rizado. }\end{array}$ \\
\hline
\end{tabular}




\begin{tabular}{|c|c|c|c|}
\hline \multirow{3}{*}{ 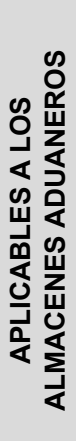 } & INFRACCIÓN & BASE LEGAL & SANCIÓN \\
\hline & $\begin{array}{l}\text { Modifiquen o reubiquen las áreas y } \\
\text { recintos sin autorización de la auto- } \\
\text { ridad aduanera. }\end{array}$ & $\begin{array}{l}\text { Numeral } 8 \\
\text { Inciso f } \\
\text { Art. } 192^{\circ}\end{array}$ & $\begin{array}{l}1 \text { UIT por cada área o recinto auto- } \\
\text { rizado. }\end{array}$ \\
\hline & $\begin{array}{l}\text { Entreguen o dispongan de las mer- } \\
\text { cancías sin que la autoridad adua- } \\
\text { nera haya concedido su levante o } \\
\text { dejado sin efecto la medida preven- } \\
\text { tiva dispuesta por la autoridad adua- } \\
\text { nera. }\end{array}$ & $\begin{array}{l}\text { Numeral } 9 \\
\text { Inciso f } \\
\text { Art. } 192^{\circ}\end{array}$ & $\begin{array}{l}\text { Equivalente al valor FOB de la mer- } \\
\text { cancía hasta un máximo de } 30 \text { UIT y } \\
\text { un mínimo de } 0,5 \text { UIT. Solo en los ca- } \\
\text { sos en que la autoridad aduanera no } \\
\text { pueda determinar el valor FOB de la } \\
\text { mercancía, la multa es de } 3 \text { UIT. }\end{array}$ \\
\hline
\end{tabular}

\begin{tabular}{|c|c|c|c|}
\hline \multirow[b]{2}{*}{ 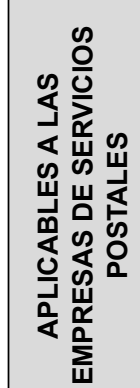 } & INFRACCIÓN & BASE LEGAL & SANCIÓN \\
\hline & $\begin{array}{l}\text { No mantengan o no se adecuen a } \\
\text { los requisitos y condiciones esta- } \\
\text { blecidos para operar. }\end{array}$ & $\begin{array}{l}\text { Numeral } 5 \\
\text { Inciso g } \\
\text { Art. } 192^{\circ}\end{array}$ & $\begin{array}{l}0,1 \text { UIT por cada requisito documen- } \\
\text { tario. } \\
1 \text { UIT por cada requisito o condición } \\
\text { de infraestructura incumplida. }\end{array}$ \\
\hline
\end{tabular}

\begin{tabular}{|c|c|c|c|}
\hline \multirow[b]{2}{*}{ 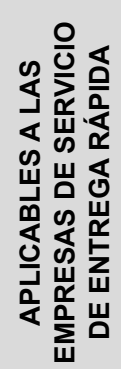 } & INFRACCIÓN & BASE LEGAL & SANCIÓN \\
\hline & $\begin{array}{l}\text { No mantengan o no se adecuen a } \\
\text { los requisitos y condiciones esta- } \\
\text { blecidos para operar. }\end{array}$ & $\begin{array}{l}\text { Numeral } 6 \\
\text { Inciso } \mathrm{h} \\
\text { Art. } 192^{\circ}\end{array}$ & $\begin{array}{l}0,1 \text { UIT por cada requisito documen- } \\
\text { tario. } \\
1 \text { UIT por cada requisito o condición } \\
\text { de infraestructura incumplida. }\end{array}$ \\
\hline
\end{tabular}

Asimismo, como consecuencia de la modificación realizada al proceso de ingreso y salida de mercancías, medios de transporte y personas, debido a la dinámica del comercio exterior y la rapidez con que se generan los cambios, se tuvieron que modificar también las infracciones aduaneras relacionadas con la no transmisión o entrega de información y entrega de la carga. Cabe indicar que a través del término "actos" se consolidó la siguiente información: "Comunicación de la fecha y hora de llegada, fecha del término de la descarga, fecha del término de embarque, entre otros". Por otra parte, se establece la obligación de los almacenes aduaneros 
de transmitir la información relacionada con la carga que reciben o que deben recibir, lo que conllevó a que se realicen modificaciones a la tipificación de las infracciones y sanciones, tal como se detalla a continuación:

\begin{tabular}{|c|c|c|c|}
\hline \multirow[b]{2}{*}{ 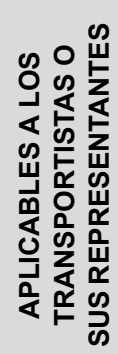 } & INFRACCIÓN & BASE LEGAL & SANCIÓN \\
\hline & $\begin{array}{l}\text { No entreguen al dueño, al consig- } \\
\text { natario o al responsable del alma- } \\
\text { cén aduanero, cuando correspon- } \\
\text { da, las mercancías descargadas, } \\
\text { conforme a lo establecido en la nor- } \\
\text { mativa vigente. }\end{array}$ & $\begin{array}{l}\text { Numeral } 1 \\
\text { Inciso d } \\
\text { Art. } 192^{\circ}\end{array}$ & $\begin{array}{l}\text { Equivalente al valor FOB determina- } \\
\text { do por la ADUANA. }\end{array}$ \\
\hline
\end{tabular}

\begin{tabular}{|c|c|c|c|}
\hline \multirow[b]{2}{*}{ 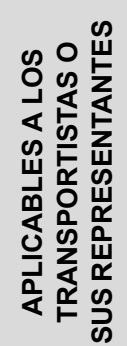 } & INFRACCIÓN & BASE LEGAL & SANCIÓN \\
\hline & $\begin{array}{l}\text { No transmitan o no entreguen a la } \\
\text { Administración Aduanera la infor- } \\
\text { mación del manifiesto de carga de } \\
\text { los otros documentos o de los actos } \\
\text { relacionados con el ingreso o salida } \\
\text { de las mercancías, conforme a lo } \\
\text { establecido en la normativa vigente. }\end{array}$ & $\begin{array}{l}\text { Numeral } 2 \\
\text { Inciso d } \\
\text { Art. } 192^{\circ}\end{array}$ & $\begin{array}{l}1 \text { UIT por no transmitir o no entregar } \\
\text { a la ADUANA la información del: } \\
\text { - Manfiesto de Carga. } \\
\text { - Descarga de la mercancía y carga } \\
\text { a embarcar. } \\
0,1 \text { UIT para los demás casos. }\end{array}$ \\
\hline
\end{tabular}

\begin{tabular}{|c|c|c|c|}
\hline \multirow{3}{*}{ 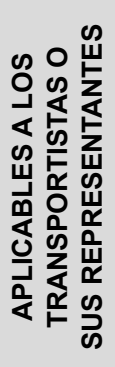 } & INFRACCIÓN & BASE LEGAL & SANCIÓN \\
\hline & $\begin{array}{l}\text { Se evidencie la falta o pérdida de } \\
\text { las mercancías bajo su responsabi- } \\
\text { lidad. }\end{array}$ & $\begin{array}{l}\text { Numeral } 3 \\
\text { Inciso d } \\
\text { Art. } 192^{\circ}\end{array}$ & $\begin{array}{l}\text { Equivalente al valor FOB determina- } \\
\text { do por la ADUANA. }\end{array}$ \\
\hline & $\begin{array}{l}\text { Los documentos de transporte no } \\
\text { figuren en los manifiestos de carga, } \\
\text { salvo que estos se hayan consigna- } \\
\text { do correctamente en la declaración. }\end{array}$ & $\begin{array}{l}\text { Numeral } 4 \\
\text { Inciso d } \\
\text { Art. } 192^{\circ}\end{array}$ & $\begin{array}{l}1 \text { UIT en la vía marítima. } \\
0,5 \text { en la vía aérea, terrestre, fluvial } \\
\text { y demás. }\end{array}$ \\
\hline
\end{tabular}

\begin{tabular}{|c|c|c|c|}
\hline \multirow[b]{2}{*}{ 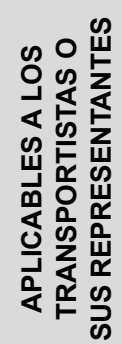 } & INFRACCIÓN & BASE LEGAL & SANCIÓN \\
\hline & $\begin{array}{l}\text { La autoridad aduanera verifique di- } \\
\text { ferencia entre las mercancías que } \\
\text { contienen los bultos y la descripción } \\
\text { consignada en los manifiestos de } \\
\text { carga, salvo que la mercancía se } \\
\text { encuentre consignada correctamen- } \\
\text { te en la declaración. }\end{array}$ & $\begin{array}{l}\text { Numeral } 5 \\
\text { Inciso d } \\
\text { Art. } 192^{\circ}\end{array}$ & $\begin{array}{l}0,2 \text { UIT en la vía marítima. } \\
0,1 \text { en la vía aérea, terrestre, fluvial y } \\
\text { demás. }\end{array}$ \\
\hline
\end{tabular}




\begin{tabular}{|c|c|c|c|}
\hline \multirow[b]{2}{*}{ 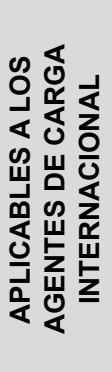 } & INFRACCIÓN & BASE LEGAL & SANCIÓN \\
\hline & $\begin{array}{l}\text { No transmitan o no entreguen a la } \\
\text { Administración Aduanera la informa- } \\
\text { ción del manifiesto de carga descon- } \\
\text { solidado o consolidado, de los otros } \\
\text { documentos o de los actos relacio- } \\
\text { nados con el ingreso o salida de las } \\
\text { mercancías, conforme a lo estable- } \\
\text { cido en la normativa vigente. }\end{array}$ & $\begin{array}{l}\text { Numeral } 1 \\
\text { Inciso e } \\
\text { Art. } 192^{\circ}\end{array}$ & $\begin{array}{l}1 \text { UIT por no transmitir o no entregar } \\
\text { a la aduana la información del mani- } \\
\text { fiesto de carga desconsolidado o con- } \\
\text { solidado. }\end{array}$ \\
\hline
\end{tabular}

\begin{tabular}{|c|c|c|c|}
\hline \multirow[b]{2}{*}{ 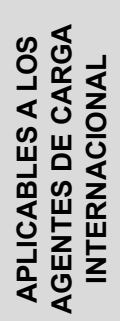 } & INFRACCIÓN & BASE LEGAL & SANCIÓN \\
\hline & $\begin{array}{l}\text { Los documentos de transporte no } \\
\text { figuren en los manifiestos de carga } \\
\text { consolidado y desconsolidado, sal- } \\
\text { vo que estos se hayan consignado } \\
\text { correctamente en la declaración. }\end{array}$ & $\begin{array}{c}\text { Numeral } 2 \\
\text { Inciso e } \\
\text { Art. } 192^{\circ}\end{array}$ & $\begin{array}{l}0,1 \text { UIT en la vía marítima. } \\
0,5 \text { en la vía aérea, terrestre, fluvial y } \\
\text { demás. }\end{array}$ \\
\hline
\end{tabular}

\begin{tabular}{|c|c|c|c|}
\hline & INFRACCIÓN & BASE LEGAL & SANCIÓN \\
\hline 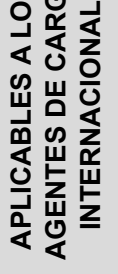 & $\begin{array}{l}\text { La autoridad aduanera verifique di- } \\
\text { ferencia entre las mercancías que } \\
\text { contienen los bultos y la descripción } \\
\text { consignada en dichos manifiestos, } \\
\text { salvo que la mercancía se encuen- } \\
\text { tre consignada correctamente en la } \\
\text { declaración. }\end{array}$ & $\begin{array}{l}\text { Numeral } 3 \\
\text { Inciso e } \\
\text { Art. } 192^{\circ}\end{array}$ & $\begin{array}{l}0,2 \text { UIT en la vía marítima. } \\
0,1 \text { en la vía aérea, terrestre, fluvial y } \\
\text { demás. }\end{array}$ \\
\hline
\end{tabular}

\begin{tabular}{|c|c|c|c|}
\hline & INFRACCIÓN & BASE LEGAL & SANCIÓN \\
\hline 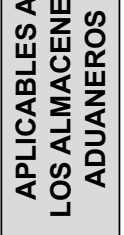 & $\begin{array}{l}\text { No transmitan o no entreguen a la Ad- } \\
\text { ministración Aduanera la información } \\
\text { relacionada con las mercancías que } \\
\text { reciben o debieron recibir, conforme a } \\
\text { lo establecido en la normativa vigente. }\end{array}$ & $\begin{array}{c}\text { Numeral } 3 \\
\text { Inciso f } \\
\text { Art. } 192^{\circ}\end{array}$ & $\begin{array}{l}1 \text { UIT por no transmitir o no en- } \\
\text { tregar a la autoridad aduanera la } \\
\text { información relacionada con el in- } \\
\text { greso y recepción de la mercancía. } \\
0,1 \text { UIT para los demás casos. }\end{array}$ \\
\hline
\end{tabular}


Con relación a la aplicación de las sanciones de multas a los transportistas previstas en los numerales 2 y 6, inciso d) del artículo $192^{\circ}$ de la Ley General de Aduanas aprobada por Decreto Legislativo No 1053, la Sala de Aduanas mediante Resolución del Tribunal Fiscal N ${ }^{\circ}$ 05296-A-2011 dispuso lo siguiente:

(...) al haberse duplicado el mismo número de Guía Aérea en dos documentos distintos, ello constituye la razón de la solicitud de rectificación por lo que es evidente que la recurrente hizo uso del derecho que la ley franquea, rectificación que fue aceptada por la Administración (...), por lo que nos encontramos frente a un caso de duplicidad del número de guía aérea en diferentes Manifiestos de Carga de Salida (...), no existiendo omisión de presentar la Guía Aérea No (...) correspondiente al Manifiesto de Carga de Salida No (...) como lo señala la Administración; por lo tanto, no se encuentra acreditada objetivamente que se haya incurrido en los supuestos de infracción previstos en los numerales 2 y 6 , inciso d) del artículo $192^{\circ}$ de la Ley General de Aduanas aprobada por Decreto Legislativo No 1053.

Asimismo, con relación a la infracción prevista en el numeral 5 del inciso d) del artículo 1920 de la Ley General de Aduanas aprobada por Decreto Legislativo № 1053, mediante Resolución del Tribunal Fiscal № 05296-A-2011 se dispuso lo siguiente:

(...) recurrente sostiene que el robo de las mercancías perpetuado en su perjuicio configura un supuesto de caso fortuito o fuerza mayor, producto del cual se vio impedido de cumplir con su obligación de entregar las mercancías, asimismo señala que tanto el Certificado de Averías como el Recibo de Indemnización expedido por la empresa aseguradora son medios probatorios idóneos que lo eximen de responsabilidad por la sustracción (robo) de las mercancías; el artículo $32^{\circ}$ del Reglamento, aprobado por D. S. No 011-2005-EF, disponía que: "La responsabilidad del transportista o su representante en el país por los bultos y/o mercancías a granel manifestados concluirá con la entrega a los almacenes aduaneros o a los dueños o consignatarios;

(...) la responsabilidad del transportista por las mercancías que traslada no concluye en el momento que estas son descargadas del medio de transporte que arribó, sino que cesa cuando la mercancía es entregada al almacén aduanero designado, con la suscripción de la respectiva nota de tarja por parte del transportista y del respectivo almacén; (...) Resoluciones del Tribunal Fiscal No 12127-A-2013, 12356-A-2009, 12869-A-2009 y 01058-A-2003, entre otras, la presentación de la denuncia, constatación policial o parte policial, sobre un robo no acredita el hecho del robo o intento de robo y/o la producción de daños, sino solo su denuncia y las investigaciones que pudiera haber realizado la policía y, por tanto, tal instrumento resulta insuficiente para acreditar en el presente caso, la materialización de un robo del Contenedor $\mathrm{N}^{\circ}(\ldots)$ por parte de terceros y que además tal circunstancia exonere de responsabilidad a la recurrente;

(...) de acuerdo a los elementos de juicio que obran en los actuados y a las normas invocadas, el transportista o su representante resulta ser el responsable por las mercancías faltantes, 
ya que no ha acreditado que hayan sido entregadas al almacén aduanero con la respectiva Nota de Tarja, así como tampoco ha logrado justificar la pérdida de las mismas.

Además, con relación al supuesto de infracción señalado en el numeral 6 del inciso d) del artículo $192^{\circ}$ de la Ley General de Aduanas aprobada por Decreto Legislativo No 1053, mediante Resolución del Tribunal Fiscal N 12554-A-2015 se dispuso lo siguiente:

(...) a fin de que se considere su acogimiento a la excepción señalada en la segunda parte del numeral 6 del inciso d) del artículo $192^{\circ}(\ldots)$, se debe cumplir 2 presupuestos:

- La presentación de una declaración aduanera antes de incumplida la obligación del transportista.

- Que en la referida declaración aduanera se haya consignado correctamente el documento de transporte.

(...) es necesario que antes de la transmisión de los Manifiestos de Carga de Salida $\mathrm{N}^{\circ}(\ldots)$ se haya consignado correctamente en las declaraciones aduaneras de exportación los documentos de transporte;

(...) conforme lo verificado en los actuados los documentos de transporte (...), fueron consignados en las Declaraciones de Exportación (de regularización, código 41) las cuales son de fechas posteriores a la transmisión de los Manifiestos de Carga de Salida, siendo por ende que las referidas declaraciones aduaneras no fueron presentadas con anterioridad, por lo que no le es aplicable la excepción (...).

Por otro lado, se modifica el artículo $203^{\circ}$ de la Ley General de Aduanas, referente a las infracciones excluidas del Régimen de Incentivos, al establecer que quedan excluidas del régimen de incentivos las infracciones tipificadas, entre otras: en los numerales 11, 12, 13, 14, 15 y 16 del literal b), numeral 4 del literal d), numerales 6, 7, 8 y 9 del literal f), numeral 5 del literal g) y numeral 6 del literal h) del artículo $192^{\circ}$ de la citada ley. La referida incorporación obedece a que estas infracciones corresponden a hechos graves, tal es el caso, por ejemplo, de disponer mercancías sin levante autorizado y presentar declaración aduanera con datos distintos a los transmitidos, los cuales eran sancionados con suspensión de actividades, y por ende, no deberían ser disminuidas las sanciones con el mencionado beneficio de la reducción del pago de multa.

Por último, se tiene que al modificarse el artículo $197^{\circ}$ de la Ley General de Aduanas se permite que el turista pueda retirar su vehículo del país, si dentro de los 30 días hábiles posteriores al vencimiento del plazo de permanencia concedido por la aduana, cumple con pagar una multa ${ }^{16}$ equivalente a 0,1 UIT el día calendario siguiente al vencimiento del plazo, más

16 Mediante Decreto Supremo N²95-2016-SUNAT, se modificó la Tabla de Sanciones. 
0,025 UIT por cada día calendario adicional hasta el día del pago de la multa. Es importante precisar que la referida multa se encuentra dentro de los alcances del régimen de incentivos, pudiéndose en este caso rebajar hasta un $90 \%$. Asimismo, una vez cancelada la multa, el beneficiario debe retirar el vehículo del país dentro de las 48 horas siguientes de realizado dicho acto o en el plazo que establezca la SUNAT, cuando el vehículo vaya a ser retirado del país por una vía distinta a la terrestre, o se presente un caso fortuito o de fuerza mayor, u otro supuesto previsto por la SUNAT.

\begin{tabular}{|c|c|c|c|}
\hline $\begin{array}{c}\text { OPERADOR } \\
\text { DE COMERCIO } \\
\text { EXTERIOR }\end{array}$ & INFRACCIÓN & BASE LEGAL & SANCIÓN \\
\hline A los turistas & $\begin{array}{l}\text { No retirar del país el vehículo } \\
\text { con fines turísticos al haber ex- } \\
\text { cedido el plazo de permanen- } \\
\text { cia concedido por la autoridad } \\
\text { aduanera y opte por retirar del } \\
\text { país el vehículo en comiso con- } \\
\text { forme al segundo párrafo del } \\
\text { artículo 197 de la L.G.A. }\end{array}$ & $\begin{array}{c}\text { Segundo } \\
\text { párrafo } \\
\text { Art. 1970 }\end{array}$ & $\begin{array}{l}\text { 0,1 UIT el día calendario siguien- } \\
\text { te al vencimiento del plazo, más } \\
0,025 \text { UIT por cada día calen- } \\
\text { dario adicional hasta el día del } \\
\text { pago de la multa. }\end{array}$ \\
\hline
\end{tabular}

\section{INFRACCIONES SANCIONABLES CON SUSPENSIÓN}

Las sanciones de suspensión establecidas en el artículo $194^{\circ}$ de la Ley General de Aduanas son aplicadas a la persona natural o jurídica, autorizada bajo un mismo Código a operar, y determinan la suspensión de su autorización a nivel nacional, es decir, en todas las circunscripciones aduaneras autorizadas. No obstante, se debe considerar que por tratarse de sanciones de naturaleza administrativa se debe tomar en cuenta para su aplicación, el principio de razonabilidad consagrado en el artículo IV numeral 1 inciso 1.4 del Título Preliminar de la Ley $\mathrm{N}^{\circ} 27444 ;{ }^{17}$ de igual modo se debe tener en cuenta lo dispuesto en el numeral 3 del artículo $230^{\circ}$ de la citada Ley; ${ }^{18}$ en consecuencia, existen casos en los que por la gravedad de

17 1.4. Principio de razonabilidad.- Las decisiones de la autoridad administrativa, cuando creen obligaciones, califiquen infracciones, impongan sanciones o establezcan restricciones a los administrados, deben adaptarse dentro de los límites de la facultad atribuida y manteniendo la debida proporción entre los medios a emplear y los fines públicos que deba tutelar, a fin de que respondan a lo estrictamente necesario para la satisfacción de su cometido.

18 3. Razonabilidad.- Las autoridades deben prever que la comisión de la conducta sancionable no resulte más ventajosa para el infractor que cumplir las normas infringidas o asumir la sanción. Sin embargo, las sanciones a ser aplicadas deberán ser proporcionales al incumplimiento calificado como infracción, debiendo observar los siguientes criterios que en orden de prelación se señalan a efectos de su graduación:

a) La gravedad del daño al interés público y/o bien jurídico protegido;

b) El perjuicio económico causado;

c) La repetición y/o continuidad en la comisión de la infracción;

d) Las circunstancias de la comisión de la infracción;

e) EI beneficio ilegalmente obtenido; $y$

f) La existencia o no de intencionalidad en la conducta del infractor. 
la infracción y de las circunstancias de su comisión no ameritan una suspensión de la autorización del operador de comercio exterior para operar a nivel nacional, sino solo a nivel de la circunscripción aduanera en la que se detectó la infracción.

En ese sentido, se incorpora un último párrafo al referido artículo $194^{\circ}$, que tiene por finalidad permitir a la Administración Aduanera aplicar la sanción de suspensión en una, en varias o en todas las circunscripciones aduaneras en que el operador de comercio exterior está autorizado a operar, conforme se establezca en la Tabla de Sanciones aplicables a las infracciones previstas en la Ley General de Aduanas.

Asimismo, se dispuso eliminar las sanciones de suspensión previstas en el numeral 6 del literal a) y el numeral 7 del literal b) aplicables a los almacenes aduaneros y despachadores de aduana respectivamente, cuando el representante legal, los gerentes o los socios de la empresa estén procesados por delito cometido en ejercicio de sus funciones desde la expedición del auto apertorio. Esta exclusión obedece a que en el numeral 3 del literal a) y en el numeral 1 del literal b) del artículo $195^{\circ}$ se contempla como causal sancionable con cancelación la condena con sentencia firme por delitos cometidos en ocasión del ejercicio de sus funciones, considerándose innecesario sancionar a los citados operadores de comercio exterior cuando se encuentre en curso un proceso penal contra sus representantes o principales funcionarios, el cual todavía no ha concluido.

De acuerdo a lo antes mencionado, son causales de suspensión solo los siguientes supuestos:

\begin{tabular}{|c|c|c|c|}
\hline $\begin{array}{l}\text { OPERADOR } \\
\text { DE COMERCIO } \\
\text { EXTERIOR }\end{array}$ & INFRACCIÓN & BASE LEGAL & SANCIÓN \\
\hline $\begin{array}{l}\text { Almacenes } \\
\text { Aduanero } \\
\text { Despacha- } \\
\text { dores de } \\
\text { aduana }\end{array}$ & $\begin{array}{l}\text { No repongan, renueven o ade- } \\
\text { cuen la garantía para el cumpli- } \\
\text { miento de sus obligaciones a } \\
\text { favor de la SUNAT. } \\
\text { No repongan, renueven o ade- } \\
\text { cuen la garantía para el cumpli- } \\
\text { miento de sus obligaciones a } \\
\text { favor de la SUNAT. } \\
\text { Haya sigo sancionado por la } \\
\text { comisión de infracción adminis- } \\
\text { trativa, prevista en la Ley de los } \\
\text { Delitos Aduanero, tratándose } \\
\text { de persona natural. }\end{array}$ & $\begin{array}{l}\text { Numeral } 1 \\
\text { Inciso b } \\
\text { Art. } 194^{\circ} \\
\\
\text { Numeral } 2 \\
\text { Inciso b } \\
\text { Art. } 194^{\circ}\end{array}$ & $\begin{array}{l}\text { Suspensión hasta la regulariza- } \\
\text { ción con un mínimo de un (01) } \\
\text { día. } \\
\text { Suspensión hasta la regulariza- } \\
\text { ción con un mínimo de un (01) } \\
\text { día. } \\
\text { Suspensión por quince (15) días } \\
\text { calendario. }\end{array}$ \\
\hline
\end{tabular}




\begin{tabular}{|l|l|l|l|}
\hline $\begin{array}{l}\text { OPERADOR } \\
\text { DE COMERCIO } \\
\text { EXTERIOR }\end{array}$ & \multicolumn{1}{|c|}{ INFRACCIÓN } & BASE LEGAL & SANCIÓN \\
\hline $\begin{array}{l}\text { Empresas } \\
\text { del servicio } \\
\text { postal }\end{array}$ & $\begin{array}{l}\text { No repongan, renueven o ade- } \\
\text { cuen la garantía para el cumpli- } \\
\text { miento de sus obligaciones a } \\
\text { favor de la SUNAT. }\end{array}$ & $\begin{array}{c}\text { Numeral 1 } \\
\text { Inciso c } \\
\text { Art. 194 }\end{array}$ & $\begin{array}{l}\text { Suspensión hasta la regulariza- } \\
\text { ción. }\end{array}$ \\
$\begin{array}{l}\text { Empresas } \\
\text { del servicio } \\
\text { de entrega } \\
\text { rápida }\end{array}$ & $\begin{array}{l}\text { No repongan, renueven o ade- } \\
\text { cuen la garantía para el cumpli- } \\
\text { miento de sus obligaciones a } \\
\text { favor de la SUNAT. }\end{array}$ & $\begin{array}{c}\text { Numeral 1 } \\
\text { Inciso a } \\
\text { Art. 194 }\end{array}$ & $\begin{array}{l}\text { Suspensión hasta la regulariza- } \\
\text { ción con un mínimo de un (01) } \\
\text { día. }\end{array}$ \\
\hline
\end{tabular}

\section{INFRACCIONES SANCIONABLES CON CANCELACIÓN}

El artículo $3^{\circ}$ del Decreto Legislativo $N^{\circ} 1235$ dispuso, entre otros aspectos, la eliminación del numeral 4 del inciso b) del artículo $195^{\circ}$ de la Ley General de Aduanas aprobada por Decreto Legislativo No 1053 , toda vez que la infracción relacionada a los despachadores de aduana, referida a cuando la autoridad aduanera comprobaba que se habían destinado mercancías a nombre de un tercero, sin contar con su autorización, ya no es sancionada con cancelación sino con multa, según lo dispuesto en el numeral 16 del inciso b) del artículo $192^{\circ}$ de la Ley General de Aduanas, monto equivalente al valor FOB de la mercancía hasta un máximo de 20 UIT y un mínimo de 0,1 UIT.

\section{INFRACCIONES SANCIONABLES CON COMISO}

La Ley $N^{\circ} 30296$ ha incluido como nuevo supuesto de infracción sancionable con comiso el destinar a otras actividades el vehículo que ingreso al país temporalmente para fines de turismo, resultando necesario incorporar dicha hipótesis en la Tabla de Sanciones, razón por la que mediante Decreto Supremo No 295-2016-SUNAT se modificó la tabla de sanciones en ese sentido.

\begin{tabular}{|l|c|l|}
\hline \multicolumn{1}{|c|}{ INFRACCIÓN } & BASE LEGAL & SANCIÓN \\
\hline $\begin{array}{l}\text { Cuando el medio de transporte, que habiendo } \\
\text { ingresado al país al amparo de la legislación } \\
\text { pertinente o de un convenio internacional, ex- } \\
\text { ceda el plazo de permanencia concedido por } \\
\text { la autoridad aduanera, excepto los vehículos } \\
\text { con fines turísticos. }\end{array}$ & $\begin{array}{c}\text { Segundo } \\
\text { párrafo } 197^{\circ}\end{array}$ & Comiso. \\
& & \\
\hline
\end{tabular}




\begin{tabular}{|l|c|l|}
\hline \multicolumn{1}{|c|}{ INFRACCIÓN } & BASE LEGAL & SANCIÓN \\
\hline $\begin{array}{l}\text { Cuando el vehículo con fines turísticos, que } \\
\text { habiendo ingresado temporalmente al país al } \\
\text { amparo de la legislación pertinente o de un } \\
\text { convenio internacional, se encuentre en las } \\
\text { siguientes situaciones: }\end{array}$ & $\begin{array}{c}\text { Segundo } \\
\text { párrafo } \\
\text { Art. } 197^{\circ}\end{array}$ & Comiso. \\
a) ha excedido el plazo de permanencia con- \\
cedido por la autoridad aduanera y no ha pa- \\
gado la multa en el plazo establecido, o \\
b) no ha sido retirado del país en el plazo es- \\
tablecido en su Reglamento.
\end{tabular}

\begin{tabular}{|l|c|l|}
\hline \multicolumn{1}{|c|}{ INFRACCIÓN } & BASE LEGAL & SANCIÓN \\
\hline $\begin{array}{l}\text { Cuando el vehículo con fines turísticos, que } \\
\text { habiendo ingresado temporalmente al país al } \\
\text { amparo de la legislación pertinente o de un } \\
\text { convenio internacional, ha sido destinado a } \\
\text { otro fin. }\end{array}$ & $\begin{array}{c}\text { Tercer } \\
\text { párrafo } \\
\text { Art. } 197^{\circ}\end{array}$ & Comiso. \\
& & \\
\hline
\end{tabular}

\section{CONCLUSIONES}

1) Se incluyen como sujetos de la obligación aduanera a los administradores y concesionarios de puertos, aeropuertos y terminales terrestres, debiéndose precisar que estos no han sido calificados en estricto como operadores de comercio exterior, haciéndolos responsables por el seguimiento y cuidado de los controles aduaneros que deben realizarse respecto a la mercancía que ingresa y sale del territorio nacional.

2) La modificación del procedimiento sancionador es consecuencia de que se debe tomar en cuenta que las sanciones de suspensión, cancelación e inhabilitación a los operadores de comercio exterior pueden conllevar al quiebre de la empresa, a la reducción de puestos de trabajo y a la ralentización del comercio exterior. En ese sentido, flexibilizar la aplicación de las mismas a través de la aplicación de criterios como los hechos y las circunstancias (aplicación de la responsabilidad subjetiva) permite reducir considerablemente los impactos negativos que podrían generarse al comercio exterior (como la paralización de ciertos tramos de la cadena logística internacional).

3) El considerar ciertas sanciones de suspensión como aplicables a determinadas circunscripciones y no en todo el territorio nacional permite que se reduzca el impacto económico que sufriría el operador de comercio exterior si es que se cerraran al mismo tiempo todos sus locales en el país, por lo que dicha modificación es muy beneficiosa. 
4) Uno de los aspectos más resaltantes constituye el hecho de reemplazar las sanciones de suspensión y cancelación por sanciones de multa, pues en ocasiones la sanción de suspensión del operador de comercio exterior resultaba una medida que en muchos casos podía generar durísimas consecuencias económicas tanto para el operador afectado como para terceros; es por esa razón que se reemplazó por una multa de carácter pecuniario, considerándose que se ha trasladado únicamente al plano económico una sanción que anteriormente podía incidir de modo adicional en aspectos laborales, empresariales o de imagen de la empresa.

5) Otro cambio importantísimo es la inclusión en la normativa aduanera del concepto de "hechos y circunstancias" a fin de aplicar proporcionalmente una sanción. Este concepto, extraído del numeral 3 del artículo $6^{\circ}$ del Acuerdo sobre Facilitación del Comercio de la OMC, permite evaluar aspectos subjetivos a fin de graduar determinadas sanciones de suspensión, cancelación e inhabilitación que permanecerán vigentes en la Ley General de Aduanas, permitiendo la evaluación de aspectos tales como el perjuicio económico causado al interés fiscal, la reincidencia, las circunstancias que rodean la comisión de la infracción, los mismos que deberán ser establecidos por la Administración Aduanera, mediante la correspondiente resolución.

6) La modificación del régimen sancionador busca tutelar la función esencial de la Administración Aduanera de facilitación del comercio exterior, reforzando el otorgamiento de suficientes garantías al administrado en el proceso sancionatorio, de tal manera que la afectación o privación de sus derechos se restrinja a lo estrictamente necesario en armonía con los principios del derecho sancionador (legalidad, razonabilidad, proporcionalidad, entre otros).

\section{REFERENCIAS}

- Chu del Águila, Iván. "Infracciones tributarias en el Perú. Visión crítica a la luz del modelo estadounidense”. Revista Jurídica del Perú, tomo 81 (noviembre 2007): 132, 145, 146147.

- Cotter, Juan Patricio. Las infracciones aduaneras. segunda edición. Buenos Aires: Abeledo Perrot, 2013.

- Morón Urbina, Juan Carlos. Comentarios a la Ley del Procedimiento Administrativo General. Undécima edición. Lima: Gaceta Jurídica, 2015. 